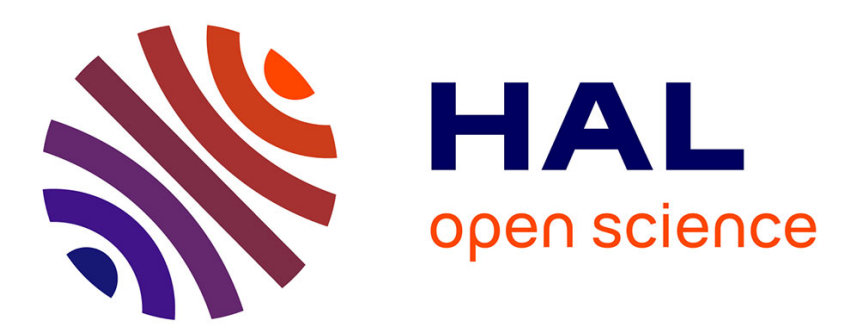

\title{
An articulatory basis for the Labial-to-Coronal effect: /pata/ seems a more stable articulatory pattern than /tapa/
} Amélie Rochet-Capellan, Jean-Luc Schwartz

\section{- To cite this version:}

Amélie Rochet-Capellan, Jean-Luc Schwartz. An articulatory basis for the Labial-to-Coronal effect: /pata/ seems a more stable articulatory pattern than/tapa/. Journal of the Acoustical Society of America, 2007, 121 (6), pp.3740-3754. 10.1121/1.2734497 . hal-00157938

\section{HAL Id: hal-00157938 \\ https://hal.science/hal-00157938}

Submitted on 27 Jun 2007

HAL is a multi-disciplinary open access archive for the deposit and dissemination of scientific research documents, whether they are published or not. The documents may come from teaching and research institutions in France or abroad, or from public or private research centers.
L'archive ouverte pluridisciplinaire HAL, est destinée au dépôt et à la diffusion de documents scientifiques de niveau recherche, publiés ou non, émanant des établissements d'enseignement et de recherche français ou étrangers, des laboratoires publics ou privés. 


\section{An articulatory basis for the Labial-to-Coronal effect:}

Amélie Rochet-Capellan and Jean-Luc Schwartz

Institut de la Communication Parlée, UMR5009 CNRS/INPG/Université Stendhal,46 
23 This paper investigates the coordination between the jaw, the tongue tip and the lower 24 lip during repetition with rate increase of Labial-to-Coronal $\left(\mathrm{L}_{\mathrm{a}} \mathrm{C}_{\mathrm{o}}\right)$ Consonant25 Vowel-Consonant-Vowel disyllables (e.g./pata/) and Coronal-to-Labial $\left(\mathrm{C}_{0} \mathrm{~L}_{\mathrm{a}}\right)$ ones 26 (e.g. /tapa/) by French speakers. For the two types of disyllables: (1) the speeding process induces a shift from two jaw cycles per disyllable to a single cycle; (2) this shift modifies the coordination between the jaw and the constrictors and (3) comes with a progression towards either a $\mathrm{L}_{\mathrm{a}} \mathrm{C}_{\mathrm{o}}$ attractor (e.g. (/pata/ or /tapa/) $\rightarrow$ /patá/ $\rightarrow$ /ptá/) or a $\mathrm{C}_{\mathrm{o}} \mathrm{L}_{\mathrm{a}}$ one (e.g. (/pata/ or /tapa/ $\rightarrow /$ tapá/ $\rightarrow /$ tpá/). Yet, (4) the $\mathrm{L}_{\mathrm{a}} \mathrm{C}_{\mathrm{o}}$ attractor is clearly favored regardless of the initial sequencing. These results are interpreted as evidence that a $\mathrm{L}_{a} \mathrm{C}_{0} \mathrm{CVCV}$ disyllable could be a more stable coordinative pattern for the lip-tongue-jaw motor system than $\mathrm{C}_{0} \mathrm{~L}_{\mathrm{a}}$ one. They are discussed in relation with the so-called LC effect that is the preference for $\mathrm{L}_{a} \mathrm{C}_{0}$ associations rather than $\mathrm{C}_{0} \mathrm{~L}_{\mathrm{a}}$ ones in CV.CV disyllables in both world languages and infants' first words. 


\section{1. Introduction}

44 The analysis of CV.CV disyllables in world languages lexicons reveals that Labial-to-

45 Coronal $\left(\mathrm{L}_{\mathrm{a}} \mathrm{C}_{\mathrm{o}}\right)$ sequences (e.g. /pata/) are about 2.5 times more used than Coronal-to-Labial

$46\left(\mathrm{C}_{\mathrm{o}} \mathrm{L}_{\mathrm{a}}\right)$ ones (e.g. /tapa/) (Locke, 1983; MacNeilage et al., 2000a, 2000b; Rousset, 2003). This

47 asymmetry, also displayed in infants' first words in the course of ontogeny (Ingram, 1974; Locke,

48 2000, MacNeilage et al., 2000a, 2000b), is known as the "LC effect". The existence of the same

49 trend in infant and adult speech lead MacNeilage and Davis (2000b) to propose a "substance-

50 based" explanation of the LC effect in the framework of the "Frame-Content Theory" of speech

51 development (MacNeilage, 1998). Yet, there are some problems with their explanation, letting

52 space for further hypotheses. The present investigation is an attempt to test an original

53 explanation of the LC effect, based on motor principles likely to intervene both in speech

54 development and in on-line adult speech production.

\subsection{The "simple first" hypothesis}

MacNeilage and Davis (2000a, 2000b) proposed that the LC effect might result from the

57 conjunction of two principles in the course of speech development: (1) labial proto-consonants

58 (or closants in the Frame-Content terminology) would be easier to produce by infants than

59 coronal ones, and (2) in order to deal with the complexity of the mental lexicon access required in

60 the production of their first words, infants would focus on easier forms. Thus, they would select

61 sequences of actions beginning by the simpler gesture, supposed to be the labial one. The

62 preference for $\mathrm{L}_{\mathrm{a}} \mathrm{C}_{\mathrm{o}}$ disyllables in development would then have been preserved in adults'

63 languages. 
The assumed greater simplicity of labial gestures is one component of the Frame-Content

65 theory of speech motor control development (MacNeilage, 1998; MacNeilage and Davis, 2000a,

66 2000b). This theory claims that speech production begins in babbling with phonation associated

67 with repeated vertical oscillations of the jaw. Apart from vocal tract pre-settings, the other

68 articulators would stay stable all along the jaw cycles. Thus, besides their alimentary function,

69 jaw cycles would induce alternation of closing and opening patterns (closants and vocants) and

70 constitute the frame of speech. Then, the speech segmental content (independent control of

71 consonants and vowels inside the frame) would progressively emerge from the development of

72 the central and peripheral motor control of the other articulators. According to MacNeilage and

73 Davis, for neutral vocal tract pre-setting, that is purely passive tongue and lips, jaw upwards

74 gestures would induce a labial closure of the vocal tract and so, the production of labial closants

75 ("pure frames"). On the contrary, coronal closants would require an active motion of the tongue

76 in pre-setting ("fronted frames"). Therefore, labial closures would be easier to realize than

77 coronal ones. However, the "simple first" explanation suffers in our view from several

78 weaknesses. Firstly, it is a bit ad hoc. Secondly, the "simpler" nature of labial closants in

79 babbling has been questioned by Vilain et al. (1999) in a study exploiting articulatory models of

80 the vocal tract. They compared three models with different morphologies - coming from the

81 statistical analysis of cineradiographic data recorded from three different adult speakers. They

82 simulated pure frames on the three models, by applying jaw upward commands, all other

83 articulators being kept passive, and they obtained different kinds of closures. In one model the

84 jaw raise resulted in closing the lips first, producing a labial contact, while in another one it first

85 resulted in a closure inside the vocal tract, producing a coronal contact. In the last model, a labial 
86 and a coronal contact were obtained almost in synchrony. Therefore, both /ba/, /da/ and /bda/

87 could be pure frames according to the vocal tract morphology. This could explain why analyses

88 of babbling inventories do not display a preference for labial patterns over coronal ones (Locke,

89 1983).

90 Another problem concerns the extrapolation from infants to adults. Indeed, there is no

91 reason to believe that labial plosives would stay simpler than coronal ones in adult speech, both

92 involving a specific articulatory control superimposed on the jaw, respectively for the lips in

93 labials and for the tongue in coronals (Munhall and Jones, 1998). Finally, the "simple first"

94 hypothesis tends to consider the articulatory control of $\mathrm{L}_{\mathrm{a}} \mathrm{C}_{\mathrm{o}}$ and $\mathrm{C}_{0} \mathrm{~L}_{\mathrm{a}}$ utterances as a sequence of

95 independent phonetic segments while it might be better characterized as coordinative structures

96 (Kelso et al., 1986; Nittrouer, 1991).

\subsection{An alternative hypothesis based on jaw-tongue-lips coordination}

It is widely assumed that some coordinative patterns are more stable and economic than

99 others and that the repetition of a multi-effectors gesture with rate increase would attract the

100 system toward its most stable coordinative mode. This has been first established for inter-limb

101 coordination (Hoyt and Taylor, 1981; Haken et al., 1985) and then, extended to articulators'

102 coordination in speech production (Kelso et al., 1986; Lindblom, 1990a; Kelso, 1995). Such

103 criteria of stability and economy have been introduced in substance-based criteria shaping the

104 sound systems of human languages (e.g. Stevens, 1989; Lindblom, 1990b). In this vein, it has

105 been shown that rate increase induced repeated VC syllables to switch towards cycled CV ones

106 (Stetson, 1951; Tuller and Kelso, 1991; de Jong, 2001). This led the authors to conclude that CV 
107 sequences are more stable than $\mathrm{VC}$ ones, which could explain the preference for $\mathrm{CV}$ syllables

108 over VC ones in language inventories (Redford and Diehl, 1999; Rousset, 2003).

109 These studies provide an interesting framework for attempting to anchor the LC effect in

110 the properties of the articulatory motor system rather than in a pure developmental framework.

111 More precisely, we assume that a labial constriction followed by a coronal one could be a better

112 coordinative pattern for the lip-tongue-jaw system than the coronal-then-labial one. This

113 assumption is inspired from Sato et al. (2006). The authors supposed that in CCV or CVC

114 sequences involving a labial and a coronal consonant, there was a trend to anticipate the coronal

115 constriction during the labial one, rather than the inverse. Hence, lips and tongue were more in-

116 phase in $/ \mathrm{ps} 2 /$ than in $/ \mathrm{sp} /$. The reason is that in $/ \mathrm{ps} 2 /$, the tongue tip may be prepared for $/ \mathrm{s} /$

117 during the labial closure, so that the $/ \mathrm{p} /$ release is almost synchronous with the tongue-driven

118 onset of the next /s/. On the contrary, in /spa/, the lips must stay open during the production of the

$119 \mathrm{~J} / \mathrm{s}$, before labial closure followed by the /p/ release, so that the tongue-lip synchrony is difficult

120 to achieve (see also Byrd, 1996; Zsiga, 1996; Surprenant and Goldstein, 1998, for compatible

121 data in English; and Chitoran et al., 2002 for Georgian). This articulatory asymmetry between the

122 two sequences of consonantal gestures could be a part of the LC effect explanation in both

123 language development and world languages lexicons.

\subsection{An experimental scenario}

125 The presumed greater stability of the coordination in $\mathrm{L}_{\mathrm{a}} \mathrm{C}_{\mathrm{o}}$ compared with $\mathrm{C}_{0} \mathrm{~L}_{\mathrm{a}}$ could be 126 investigated through the speeding paradigm. The slow regular repetition of $\mathrm{C}_{1} \mathrm{VC}_{2} \mathrm{~V}$ disyllables

127 should be characterized by a regular alternation of $\mathrm{C}_{1}$ and $\mathrm{C}_{2}$ gestures over time. On the contrary, 
128 rate increase could lead to asymmetries, the $\mathrm{C}_{2}$ constriction being either closer to the previous or

129 to the next $\mathrm{C}_{1}$ one. This would induce the reduction of either the vowel after $\mathrm{C}_{1}$ or after $\mathrm{C}_{2}$. The

130 French language, under study here, displays a stress on the word last syllable. Therefore, in the

131 repetition with rate increase of a CVCV disyllable, French speakers should rather reduce the first 132 vowel, and a CCV re-syllabification could be expected. Hence, two hypotheses may be

133 contrasted. In a first one, there would be no asymmetry between $\mathrm{L}_{a} \mathrm{C}_{\mathrm{o}}$ and $\mathrm{C}_{0} \mathrm{~L}_{\mathrm{a}}$ coordination, and

134 the French speakers would preserve the original disyllable prosody through speeding. In this first

135 hypothesis, $\mathrm{L}_{\mathrm{a}} \mathrm{C}_{\mathrm{o}} \mathrm{CVCV}$ sequences would evolve toward a $\mathrm{L}_{\mathrm{a}} \mathrm{C}_{\mathrm{o}}$ attractor (e.g. /pata/ $\rightarrow$ /patá/ $\rightarrow$

136 /ptá/) while $\mathrm{C}_{0} \mathrm{~L}_{\mathrm{a}} \mathrm{CVCV}$ sequences would evolve toward a $\mathrm{C}_{0} \mathrm{~L}_{\mathrm{a}} \mathrm{CCV}$ attractor (e.g. /tapa/) $\rightarrow$

137 /tapá/ $\rightarrow$ /tpá/). Yet, if, as we expect, the $\mathrm{L}_{\mathrm{a}} \mathrm{C}_{\mathrm{o}}$ coordination is more stable than the $\mathrm{C}_{\mathrm{o}} \mathrm{L}_{\mathrm{a}}$ one, this

138 would attract the system towards a $\mathrm{L}_{\mathrm{a}} \mathrm{C}_{\mathrm{o}}$ attractor regardless of the initial CVCV sequence (e.g.

139 (/pata/ or /tapa/) $\rightarrow$ /patá/ $\rightarrow$ /ptá/). Hence, in this second hypothesis, the repetition with rate

140 increase of both $\mathrm{L}_{a} \mathrm{C}_{0}$ and $\mathrm{C}_{0} \mathrm{~L}_{\mathrm{a}} \mathrm{CVCV}$ disyllables would evolve towards a $\mathrm{L}_{a} \mathrm{C}_{0}$ attractor. The

141 first experiment, based on acoustic measurements, aimed at selecting which of these two 142 assumptions is true.

143 In a second experiment based on articulatory measurements, we studied how the 144 articulatory coordination between jaw, tongue and lips would be reorganized in order to subtend 145 the progression from one constriction per jaw cycle (e.g. /pata/) towards two constrictions per jaw 146 cycle (e.g. /ptá/). A prediction was that the two constrictions would be realized on a single jaw 147 cycle before the fading of the vowel was completed (e.g. /patá). In other words, the variation of 148 the articulation place between the first and the second constriction would allow the production of 149 two syllables on a single jaw cycle, while most studies of jaw movements associate the jaw cycle 
150 with the CV syllable (Nelson et al., 1984; Ostry and Flanagan, 1989; Perkell and Zandipour, 151 2002; Perkell et al., 2002).

\section{An acoustic study of LC and CL stability}

The aim of this first study is to test if $\mathrm{L}_{\mathrm{a}} \mathrm{C}_{\mathrm{o}}$ sequences are more stable than $\mathrm{C}_{\mathrm{o}} \mathrm{L}_{\mathrm{a}}$ ones in a

154 speeding paradigm, using an acoustic measure of vowel reduction.

\subsubsection{Speakers and phonetic material}

28 native French speakers with no speech or hearing problem and naive as to the purpose

158 of the study participated in the experiment. The phonetic material consisted in six CVCV

159 disyllables: three $\mathrm{L}_{a} \mathrm{C}_{\mathrm{o}}$ (/pata/, /pasa/ and /fata/) and their three $\mathrm{C}_{\mathrm{o}} \mathrm{L}_{\mathrm{a}}$ counterparts (/tapa/, /sapa/

160 and /tafa/). This choice aimed at contrasting $\mathrm{L}_{\mathrm{a}} \mathrm{C}_{\mathrm{o}}$ and $\mathrm{C}_{\mathrm{o}} \mathrm{L}_{\mathrm{a}}$ sequences while controlling for a

161 possible "plosive-to-fricative" effect. Indeed, in the framework of "sonority" principles (Selkirk,

162 1984; Clements, 1990) it could be supposed that utterances containing a fricative and a plosive

163 would switch towards plosive-fricative attractors (e.g. /tfa/, /psa/), rather than the $\mathrm{L}_{\mathrm{a}} \mathrm{C}_{\mathrm{o}}$ attractors

$164 \mathrm{fta} /, / \mathrm{psa} /$ and $/ \mathrm{fta} /$ expected in the framework of our basic assumptions. The /a/ vowel was

165 selected to provide an open configuration, mainly involving the jaw, with basically no strong

166 requirements on the lips and the tongue. The six disyllables were randomly arranged inside three

167 lists. The three lists were presented to each speaker in different orders. Hence each disyllable was

168 presented three times to each speaker. The test began with three items provided as training

169 stimuli (/vada/, /daba/ and /dava/). 
171 In order to simplify post-treatments the experiment was assisted by a computer program

172 that allowed to record utterances and to display a kind of visual metronome. The participants

173 were sitting in front of a computer connected to a microphone. The instruction was to repeat the

174 disyllable displayed on the screen at an increased and then decreased rate following as much as

175 possible the rhythm of a visual flash. The aim of this flash was not to precisely control the

176 speakers' rate but rather to give global timing marks in order to homogenize acceleration and

177 deceleration phases between speakers and to attempt to drive the speakers to their limit rate. It

178 was mentioned that the flash would reach rates impossible to follow and the instruction was to

179 maintain a rate as high as possible during this period until the decelerating phase. Moreover,

180 speakers were encouraged to go on without interruption even if they perceived any kind of

181 transformation of the uttered sequence.

182 The experiment began by the three practice trials. Then, the three lists were successively

183 displayed. Each trial started with the presentation of the CVCV sequence to repeat, displayed in

184 the middle of the screen. Speakers initiated the flash pressing the "space" key. A blue square took

185 the place of the disyllable on the screen for one second, followed by the flash. The flash was an

186 alternation of a black and a white square. The instruction was to produce one syllable on the

187 black flash and the other on the white one. Duration of each square presentation started at $300 \mathrm{~ms}$

188 and progressively decreased to reach $125 \mathrm{~ms}$ at the middle of the acceleration phase and $50 \mathrm{~ms}$ at

189 the end of the acceleration phase $(8 \mathrm{~s})$. The progression was shaped in order to obtain a large

190 amount of rapid productions. The timing of the deceleration phase was the symmetric of the

191 acceleration one. Thus, each trial record lasted 16 s. Speakers sometimes took a breath inside the 
192 whole acceleration-deceleration process, but this occurred seldom and at random positions inside

193 the $16 \mathrm{~s}$ utterance. Then the speaker spontaneously resumed the process at about the same tempo 194 he/she had reached before the breath.

\subsubsection{Hypotheses and measurements}

The working hypothesis is that both $\mathrm{L}_{\mathrm{a}} \mathrm{C}_{\mathrm{o}}$ and $\mathrm{C}_{\mathrm{o}} \mathrm{L}_{\mathrm{a}}$ repetitions would evolve towards a

$197 \mathrm{~L}_{\mathrm{a}} \mathrm{C}_{\mathrm{o}} \mathrm{CVCV}$ sequencing until eventually reaching a $\mathrm{L}_{\mathrm{a}} \mathrm{C}_{\mathrm{o}} \mathrm{CCV}$ consonantal cluster. For example, 198 if /pata/ is indeed more stable than /tapa/, the speeding process should be: (/pata/ or /tapa/) $\rightarrow$ 199 /patá/ $\rightarrow$ /ptá/. The contrasted prediction is that, if there were no asymmetry between $\mathrm{L}_{\mathrm{a}} \mathrm{C}_{\mathrm{o}}$ and

$200 \mathrm{C}_{0} \mathrm{~L}_{\mathrm{a}}$ utterances in terms of coordinative structure, the French prosodic pattern with a stress on the

201 final syllable of a word should drive the behavior with e.g. /pata/ $\rightarrow$ /patá/ $\rightarrow$ /ptá/ and /tapa/ $\rightarrow$

202 /tapá/ $\rightarrow /$ tpá/. Finally, both trends could be observed, with a $\mathrm{L}_{a} \mathrm{C}_{0}$ vs. $\mathrm{C}_{0} \mathrm{~L}_{\mathrm{a}}$ asymmetry, 203 superimposed on an effect of the initial uttered sequence. These predictions were tested by 204 prosodic measurements based on vowel intensity. Acoustic energy was continuously estimated, 205 within the Praat software ${ }^{1}$ using a $42.6 \mathrm{~ms}$ Kaiser-20 window (sidelobes below $-190 \mathrm{~dB}$ ). 206 Maxima and minima of energy curves were automatically detected and then hand-selected as 207 vowels and consonants (Figure 1). When a speaker's production evolved towards a single 208 consonantal cluster (e.g. /ptá/), the labeling rule was to mark the "vanished" vowel and the two 209 consonants around as a same event (e.g. Figure 1, right). Speakers' errors such as repetition of a 210 single syllable or pauses were removed. From these data, two parameters were computed for each

211 CVCV or CCV sequence correctly produced (now referred as "utterances"): (1) the utterance 212 duration and (2) the variation of intensity between the two vowels, that is the difference between 
213 the intensity of the vowel after the coronal consonant $\left(\mathrm{V}_{\mathrm{Co}}\right)$ and the intensity of the vowel after

214 the labial consonant $\left(\mathrm{V}_{\mathrm{La}}\right)$ :

$$
\Delta \mathrm{I}=\mathrm{I}\left(\mathrm{V}_{\mathrm{Co}}\right)-\mathrm{I}\left(\mathrm{V}_{\mathrm{La}}\right)
$$

216 The operational hypothesis was that $\Delta \mathrm{I}$ would be positive for both the $\mathrm{L}_{\mathrm{a}} \mathrm{C}_{\mathrm{o}}$ and the $\mathrm{C}_{0} \mathrm{~L}_{\mathrm{a}}$

217 utterances for fast productions, with very high positive values indicating a shift towards a single

$218 \mathrm{~L}_{\mathrm{a}} \mathrm{C}_{\mathrm{o}} \mathrm{CCV}$ syllable (e.g. from /pata/ or /tapa/ to /ptá/, as in Figure 1). and "V" the vowel /a/ or nothing.

\subsubsection{Evolution of $\Delta I$ across rate: global tendencies}

229 The plot of $\Delta I$ values against utterance durations for all the speakers' $L_{a} C_{o}$ and $C_{0} L_{a}$ utterances 230 shows very similar patterns for the three $\mathrm{L}_{a} \mathrm{C}_{0}$ and $\mathrm{C}_{\mathrm{o}} \mathrm{L}_{\mathrm{a}}$ pairs. Hence, only the graphs for /pasa/ 231 and /sapa/ are displayed on Figure 2 (top), as a representative example. Globally and for both the $232 \mathrm{~L}_{\mathrm{a}} \mathrm{C}_{\mathrm{o}}$ (left) and $\mathrm{C}_{\mathrm{o}} \mathrm{L}_{\mathrm{a}}$ (right) groups, utterance durations range from 100 to $700 \mathrm{~ms}$. Furthermore,

$233 \Delta \mathrm{I}$ values are close to 0 for durations longer than about $300 \mathrm{~ms}$ whereas they vary from -40 to 
$23440 \mathrm{~dB}$ for shorter durations. Actually, standard deviations of $\Delta \mathrm{I}$ values (Figure 2, bottom) are 235 small above $300 \mathrm{~ms}$, and larger under $300 \mathrm{~ms}$. The shift from small to large $\Delta \mathrm{I}$ values is stable 236 around $300 \mathrm{~ms}$ for all $\mathrm{CVCV}$ sequences, leading us to select this value as a limit for further 237 analyses. Thus, for slow rates, the speakers keep a regular alternation of labial and coronal 238 syllables without any strong reduction effect. Then, rate increase induces the reduction of either

$239 \mathrm{~V}_{\mathrm{La}}$ (positive $\Delta \mathrm{I}$ values) or $\mathrm{V}_{\mathrm{Co}}$ (negative $\Delta \mathrm{I}$ values). Hence, both the $\mathrm{L}_{\mathrm{a}} \mathrm{C}_{\mathrm{o}}$ (/psá/) and the $\mathrm{C}_{\mathrm{o}} \mathrm{L}_{\mathrm{a}}$

240 (/spá/) CCV clusters seem to constitute possible attractors for the repetition of either $\mathrm{L}_{a} \mathrm{C}_{o}$ or $\mathrm{C}_{0} \mathrm{~L}_{\mathrm{a}}$

241 CVCV logatoms. Yet, the graphs display more positive than negative $\Delta \mathrm{I}$ values for the two types

242 of disyllables. Therefore, the $\mathrm{L}_{\mathrm{a}} \mathrm{C}_{\mathrm{o}}$ attractor seems to prevail over the $\mathrm{C}_{0} \mathrm{~L}_{\mathrm{a}}$ one, particularly for

243 the $\mathrm{L}_{\mathrm{a}} \mathrm{C}_{\mathrm{o}}$ trials (Figure 2, top left).

\subsubsection{Detailed analysis according to the disyllables and to the speakers}

In order to investigate more precisely possible reorganizations of productions in the

248 speeding process, the analysis of $\Delta \mathrm{I}$ was restricted to utterances with durations shorter than

$249300 \mathrm{~ms}$. In spite of the flash, the utterance durations varied a lot according to the speaker and to

250 the trial. Therefore, for the analysis, we kept only speakers achieving a sufficient amount of quick

251 data with the following criterion: for each of the six CVCV logatoms, the speaker should have

252 produced at least five quick utterances (durations shorter than $300 \mathrm{~ms}$ ) for at least two of his/her

253 three trials. Then, only the two trials with the largest number of quick utterances were analyzed.

254 This criterion excluded five speakers. In the following, only the utterances with durations less

255 than $300 \mathrm{~ms}$ are analyzed, for the two selected trials of the 21 remaining subjects. 
257 from 0 except for /sapa/ (Table I, first row). Moreover, the distribution of the 42 means according 258 to their sign (last four rows in Table I) shows that the ratio of positive means related to negative 259 ones (rows 3 and 5) is 2.5 for /pata/ and /tapa/, 7.4 for /fata/, 3.6 for /tafa/ and 1.8 for /pasa/ 260 whereas it is 1 for /sapa/. A Chi-square test shows significant difference between the frequencies 261 of positive vs. negative means $\left(\chi^{2}(1)=6.6, p<.001\right)$. Restricted to means that significantly differ 262 from 0 (rows 4 and 6 ) the prevalence of positive means over negative ones is even greater with a 263 ratio of 4.75 for $/ \mathrm{pata} /, 2.5 \mathrm{for} / \mathrm{tapa} /, 3$ for $/ \mathrm{pasa} /, 1.4 \mathrm{for} / \mathrm{sapa} /, 13$ for $/ \mathrm{fata} /$ and 5.3 for $/ \mathrm{tafa} /$ 264 (frequency of significant positive means significantly different from significant negative ones, $\left.265 \chi^{2}(1)=6.8, p<.001\right)$. Hence, the speeded repetition of $\mathrm{L}_{a} \mathrm{C}_{0}$ and $\mathrm{C}_{0} \mathrm{~L}_{\mathrm{a}} \mathrm{CVCV}$ disyllables more 266 often evolves towards the corresponding $\mathrm{L}_{\mathrm{a}} \mathrm{C}_{\mathrm{o}}$ attractor (eg. /pasá/ or /psá/) than the $\mathrm{C}_{\mathrm{o}} \mathrm{L}_{\mathrm{a}}$ one (eg.

267 /sapá/ or /spá/). However, $\mathrm{C}_{0} \mathrm{~L}_{\mathrm{a}}$ forms appear in some cases for both $\mathrm{L}_{a} \mathrm{C}_{\mathrm{o}}$ and $\mathrm{C}_{0} \mathrm{~L}_{\mathrm{a}}$ trials. 268 Furthermore, two additional factors tend to emerge. Indeed, there is some trend that $\Delta \mathrm{I}$ values are 269 larger, and more systematically positive, for $\mathrm{L}_{a} \mathrm{C}_{\mathrm{o}}$ than for $\mathrm{C}_{\mathrm{o}} \mathrm{L}_{\mathrm{a}}$ trials on one hand, and for /pata/$270 \mathrm{Jtapa} /$ and /fata/-/tafa/ than for /pasa/-/sapa/ trials on the other hand.

277 speaker and for each CVCV sequence, provided that the two means significantly differed from 0. 
278 It appears that mean $\Delta \mathrm{I}$ values are both significantly positive for 41 cases, both significantly 279 negative for 7 cases and have different signs in 5 cases. Therefore, the dominant behavior is to 280 evolve towards the same attractor for the two trials with a large preference for the $\mathrm{L}_{\mathrm{a}} \mathrm{C}_{\mathrm{o}}$ compared 281 to the $\mathrm{C}_{0} \mathrm{~L}_{\mathrm{a}}$ one. Yet, in some cases, the attractor differs from one trial to the other. Then, 282 grouping all logatoms, it appears that some speakers tend to be " $\mathrm{L}_{\mathrm{a}} \mathrm{C}_{\mathrm{o}}$ stable" (e.g. S12, right part 283 of the Figure 3) whereas others are, in a lower extend, rather " $\mathrm{C}_{0} \mathrm{~L}_{\mathrm{a}}$ stable" (e.g. S23). Finally, 284 some speakers are "bi-stable": the category of attractor they evolved towards changes according 285 to the trial (S20) or to the logatom (S6).

In summary, the speeded repetition of $\mathrm{L}_{\mathrm{a}} \mathrm{C}_{0}$ and $\mathrm{C}_{0} \mathrm{~L}_{\mathrm{a}}$ logatoms could evolve both

290 towards the $\mathrm{L}_{a} \mathrm{C}_{0}$ or the $\mathrm{C}_{0} \mathrm{~L}_{\mathrm{a}}$ attractor. Yet, and despite variability between disyllables and

291 between speakers, the $\mathrm{L}_{a} \mathrm{C}_{0}$ attractors are largely favored compared to the $\mathrm{C}_{\mathrm{o}} \mathrm{L}_{\mathrm{a}}$ ones. Thus, /patá/292 /ptá/ is the favorite attractor for /pata/ and /tapa/; /pasá/-/psá/ for /pasa/ and to a lower extend for 293 /sapa/ and /fatá/-/ftá/ for both/fata/ and/tafa/.

\section{An articulatory study of $\mathrm{L}_{\mathrm{a}} \mathrm{C}_{\mathrm{o}}$ and $\mathrm{C}_{\mathrm{o}} \mathrm{L}_{\mathrm{a}}$ stability}

The main purpose of the second study is to understand from EMMA recordings how the

296 articulatory system could evolve with rate increase from a $\mathrm{L}_{a} \mathrm{C}_{0}$ or a $\mathrm{C}_{0} \mathrm{~L}_{\mathrm{a}} \mathrm{CVCV}$ disyllable

297 towards either a $L_{a} C_{0}$ or a $C_{0} L_{a}$ attractor, with a preference for the first one. 


\subsubsection{Speakers and phonetic material}

301 and two males - S2 and S5), without any speech or hearing deficits. They did not participate in

302 Experiment 1 . The $\mathrm{L}_{\mathrm{a}} \mathrm{C}_{\mathrm{o}}$ and $\mathrm{C}_{\mathrm{o}} \mathrm{L}_{\mathrm{a}}$ disyllables were the same as in the acoustic study. Two 303 duplicated CVCV logatoms (/papa/ and /tata/) were added as control items.

\subsubsection{Procedure, data recording and processing}

The instruction was to continuously repeat the disyllable enounced by the experimenter starting at a slow rate and then at an increasingly rapid rate up to the highest possible one. The

307 speakers then had to progressively decrease the rate to return to the initial slow one. Contrary to

308 the first experiment, no external tempo driver was used because of the already difficult conditions

309 of EMMA recording. Speakers were encouraged not to stop their productions even if they seemed

310 different from the initial sequence. The eight disyllables were repeated three times with orders

311 that varied from one subject to another. The articulator motions were tracked over time at $500 \mathrm{~Hz}$

312 using a Cartens Electromagnetic Articulograph. Two reference transducers, one at the bridge of

313 the nose and the other on the gums above the upper teeth allowed to correct the data for head

314 movements. The three measurement points were: the jaw (transducer placed beneath the lower

315 teeth); the Tongue Tip (TT, transducer placed at about $1 \mathrm{~cm}$ from the tip of the tongue) and the

316 Lower Lip (LL, transducer just beneath the vermilion border of the lower lip). These raw

317 measurements were then processed according to classical procedures (see Hoole P., 1996 for

318 more details). These involved translation and rotation correcting for head movement, resulting in 
319 setting the origin at the reference coil located on the upper incisors, the vertical axis as the line

320 joining the reference coils on upper incisors and nose bridge, and the x-axis aligned with the

321 occlusal plane. The acoustic signal was simultaneously recorded by the way of a microphone

322 fixed on the articulograph helmet and then digitized at $20 \mathrm{kHz}$.

\subsubsection{Hypotheses}

324 The first hypothesis is that the mandible would evolve from a one-cycle-per-syllable 325 relationship to a one-cycle-per-disyllable relationship when speeding $\mathrm{L}_{\mathrm{a}} \mathrm{C}_{\mathrm{o}}$ or $\mathrm{C}_{\mathrm{o}} \mathrm{L}_{\mathrm{a}} \mathrm{CVCV}$ 326 logatoms. However, duplicated $\mathrm{L}_{\mathrm{a}} \mathrm{L}_{\mathrm{a}}(/ \mathrm{papa} /)$ or $\mathrm{C}_{\mathrm{o}} \mathrm{C}_{\mathrm{o}}$ (/tata/) CVCV logatoms were expected not 327 to display this behavior. The second hypothesis concerns the lips-tongue coordination inside a 328 single jaw cycle at high rates. Two attractors were expected, either $\mathrm{L}_{\mathrm{a}} \mathrm{C}_{\mathrm{o}}$ or $\mathrm{C}_{\mathrm{o}} \mathrm{L}_{\mathrm{a}}$. In the first case, 329 the labial constriction and the next coronal constriction (respectively maximum values of LL and

330 TT trajectories) should be close together. In the second case, the coronal constriction should be 331 close to the next labial one. Considering the small number of speakers, and the variability 332 observed in the first experiment, no strong claim was made about a preference for $\mathrm{L}_{\mathrm{a}} \mathrm{C}_{\mathrm{o}}$ attractors. 333 Instead, the hope was that inter-speaker variability would enable to observe both kinds of 334 attractors, in order to be able to characterize them articulatorily. 
339 Processing of acoustical data was the same as in Experiment 1. It led to computation of

340 the duration and intensity variation between the two vowels $(\Delta \mathrm{I})$ for each utterance $(\mathrm{CVCV}$ or

341 CCV items correctly produced). Articulatory analysis used articulator trajectories preprocessed

342 by a low-pass Chebychev filter (cutting frequency at $15 \mathrm{~Hz}$ ). Jaw maxima and minima (Figure 4,

343 row 2) were automatically detected on the jaw trajectory, allowing its segmentation into closing

344 and opening phases (up and down strokes). Post-processing discarded movements realized during

345 pauses or errors (detected from the acoustical labeling). For the correct utterances, two criteria

346 were used in order to discard productions subtended by too small jaw movements. Firstly, we

347 checked for the regular alternation of opening and closing strokes; secondly, we removed strokes

348 with an amplitude lower than $0.1 \mathrm{~mm}$, which is the claimed precision of the EMMA system.

349 Table II summarizes the total number of correct utterances and the number of correct utterances

350 kept for further articulatory analysis. Then, TT and LL events were labeling on articulatory

351 signals, with the help of acoustic events. TT constrictions were defined as the highest TT

352 positions between the vowel after the labial consonant $\left(\mathrm{V}_{\mathrm{La}}\right)$ and the vowel after the coronal

353 consonant $\left(\mathrm{V}_{\mathrm{Co}}\right)$ (Figure 4, row 3). Similarly, LL constrictions were defined as the highest LL

354 positions between $\mathrm{V}_{\mathrm{Co}}$ and $\mathrm{V}_{\mathrm{La}}$ (Figure 4, row 4). This method (similar to Hertrich and

355 Ackermann's one, 2000) discards secondary maxima due to passive motion induced by the jaw 356 gesture that comes with the other constriction. 
361 cycle duration was the sum of its up and down stroke durations and the jaw cycle amplitude was

362 the mean of its up and down stroke amplitudes (Figure 5.A). Each constriction event was

363 assigned to the jaw cycle that temporally included it and positioned relatively to this jaw cycle

364 (Figure 5B). This measure, expressed in percent of jaw cycle, constitutes an indicator of the

365 phasing relationship between the jaw and constrictors. Finally, the coordination between TT and

366 LL was characterized by the duration of the labial-to-coronal phase (time from LL constriction to

367 TT constriction $\mathrm{D}_{\mathrm{LaC}}$ ), normalized by the whole disyllable duration (time from a LL constriction

368 to the next $\mathrm{LL}$ one $\left.\mathrm{D}_{\mathrm{LaLa}}\right)$ :

$$
\Delta_{\text {(LaCo/LaLa) }}=\mathrm{D}_{\mathrm{LaCo}} / \mathrm{D}_{\mathrm{LaLa}}
$$

\subsubsection{Acoustic analysis}

The global pattern of $\Delta \mathrm{I}$ against utterance duration for $\mathrm{L}_{\mathrm{a}} \mathrm{C}_{\mathrm{o}}$ or $\mathrm{C}_{\mathrm{o}} \mathrm{L}_{\mathrm{a}}$ sequences is very

376 close to the pattern observed in the first experiment (compare Figure 6, right, with Figure 2). That

377 is, $\Delta \mathrm{I}$ values are close to 0 for durations longer than $300 \mathrm{~ms}$ whereas $\Delta \mathrm{I}$ values far from 0 appear

378 for shorter durations, with more positive than negative values. On the contrary, $\Delta \mathrm{I}$ values are

379 always close to 0 for duplicated $\mathrm{L}_{\mathrm{a}} \mathrm{L}_{\mathrm{a}}$ or $\mathrm{C}_{0} \mathrm{C}_{\mathrm{o}}$ logatoms (Figure 6 , left). 
384 represent the panel of behaviors observed in the first experiment. Indeed, as a subset of speakers

385 of the acoustic study, S3 fails to produce enough rapid productions. This may indicate that this

386 speaker rarely shifts towards a CCV structure. Then, $\mathrm{S} 1$ and $\mathrm{S} 4$ tend to favor the $\mathrm{C}_{0} \mathrm{~L}_{\mathrm{a}}$ attractor

387 (more negative than positive means) especially for /pasa/ and /sapa/ for S1 and for the three $\mathrm{C}_{0} \mathrm{~L}_{\mathrm{a}}$

388 disyllables for S4. On the contrary S2 and S5 tend to favor the $\mathrm{L}_{\mathrm{a}} \mathrm{C}_{\mathrm{o}}$ attractor for all disyllables

389 except for S5's /sapa/ productions. Interestingly, these behaviors correspond to both the speakers'

390 profiles and the variability between sequences observed in the first experiment.

\subsubsection{Global analysis of jaw cycles}

395 The /tapa/ utterance samples displayed on Figure 4 illustrate the speeding process 396 generally observed for a $\mathrm{L}_{\mathrm{a}} \mathrm{C}_{\mathrm{o}}$ or a $\mathrm{C}_{\mathrm{o}} \mathrm{L}_{\mathrm{a}}$ trial. First, during the acceleration phase (left), each

397 constriction comes with its own jaw gesture. Yet, the amplitude and the duration of the jaw cycle

398 for the labial constrictions tend to be smaller than for the coronal constrictions. Then, rate

399 increase induces the progressive fading of the jaw cycle that supports the labial constriction,

400 resulting in a single jaw cycle for the two constrictions. For this example, the plot of the acoustic 401 signal (top) shows that the speaker does not evolve towards a CCV syllable but produces two 
402 syllables on a single jaw cycle (splitting phase, middle). Finally, the deceleration progressively

403 brings the system back to its initial state with one jaw cycle per syllable (right).

404 Plots of jaw cycle durations (y) against CVCV durations (x) for all speakers' productions

405 (Figure 7, first row) and separately for the duplicated (left) and variegated (right) CVCV 406 sequences show that duplicated productions are grouped around the $(y=x / 2)$ line (i.e. two jaw 407 cycles for one disyllable) whereas both $\mathrm{L}_{a} \mathrm{C}_{0}$ and $\mathrm{C}_{0} \mathrm{~L}_{\mathrm{a}}$ ones are distributed around the $(y=x / 2)$ and $408(y=x)$ lines (i.e. two vs. one jaw cycle per disyllable). This distribution splitting occurs for 409 utterance durations less than about $400-450 \mathrm{~ms}$. Analyses of $\Delta \mathrm{I}$ in the acoustic study showed that 410 the shift towards a CCV cluster, characterized by high $\Delta \mathrm{I}$ values, occurs for durations shorter than $411300 \mathrm{~ms}$. Therefore, the shift towards a single cycle for two syllables occurs before the total 412 suppression of one of the two vowels (that is, for longer utterance durations).

417 duplicated and the $\mathrm{L}_{\mathrm{a}} \mathrm{C}_{\mathrm{o}} / \mathrm{C}_{0} \mathrm{~L}_{\mathrm{a}}$ group. Yet, the durations of duplicated utterances are never shorter 418 than $225 \mathrm{~ms}$ and are mostly around $300 \mathrm{~ms}$ whereas around $15 \%$ of $\mathrm{L}_{\mathrm{a}} \mathrm{C}_{\mathrm{o}} / \mathrm{C}_{\mathrm{o}} \mathrm{L}_{\mathrm{a}}$ productions 419 reach durations from $175 \mathrm{~ms}$ to $225 \mathrm{~ms}$ with a peak of distribution around $250-275 \mathrm{~ms}$. On the 420 contrary, the jaw cycle durations (Figure 7, third row) are clearly shorter for the duplicated 421 productions (peak of distribution around $150 \mathrm{~ms}$ ) than for $\mathrm{L}_{\mathrm{a}} \mathrm{C}_{\mathrm{o}} / \mathrm{C}_{\mathrm{o}} \mathrm{L}_{\mathrm{a}}$ ones (peak of distribution 422 around $225 \mathrm{~ms}$ ). Finally, the jaw cycle duration is never shorter than $100 \mathrm{~ms}$ for all logatoms. 423 Altogether, this portrait is coherent with the fact that at a fast rate $\mathrm{L}_{a} \mathrm{C}_{\mathrm{o}} / \mathrm{C}_{0} \mathrm{~L}_{\mathrm{a}}$ sequences can be 
424 produced on one single jaw cycle. The progression towards a single cycle limits jaw motion and

425 keeps it at a more comfortable duration for the fastest production rates. Thus, it probably limits

426 the energy consumption.

427 In order to analyze the shift from two jaw cycles to a single one, the speaker's productions 428 were classified into three periods (e.g. Figure 4). The "splitting" phase includes the utterances 429 realized on a single jaw cycle. The "acceleration" and the "deceleration" phases include the 430 utterances realized on two jaw cycles respectively before and after the splitting phase.

\subsubsection{Patterns of jaw motion in the acceleration phase}

The amplitude and duration of jaw opening and closing strokes in the acceleration phase

433 are plotted on Figure 8, for each speaker, respectively for duplicated (left) and $\mathrm{L}_{\mathrm{a}} \mathrm{C}_{\mathrm{o}} / \mathrm{C}_{\mathrm{o}} \mathrm{L}_{\mathrm{a}}$ (right)

434 sequences. Strokes are seldom shorter than $50 \mathrm{~ms}$, which agrees with the $100 \mathrm{~ms}$ threshold 435 observed for the jaw cycle durations (Figure 7). Separate regression lines are superimposed for 436 labial and coronal cycles. In their study of jaw motion for duplicated sequences (/sa/), Nelson et 437 al. (1984) used the same kind of display. A theoretical analysis allowed the authors to define a 438 limit parabolic curve, such that for a given value of the maximum acceleration during a jaw 439 stroke, the corresponding amplitude vs. duration points were always on the right of the limit 440 parabolic curve. Without entering their explanation in too many details, the principle is basically 441 that to achieve a given trajectory extent in a given duration, the acceleration along the trajectory 442 must achieve a sufficient maximum value. Reciprocally, for a given maximum acceleration value 443 and a given trajectory extent, duration cannot be lower than a limit, specified by the parabolic 444 curve. On the figure, we have superimposed three such limit curves, respectively corresponding 445 to maximum acceleration values of $0.25 \mathrm{~g}, 0.50 \mathrm{~g}$ and $1.5 \mathrm{~g}$ (see also Nelson, 1983). 
447 different pattern from speakers S1, S2 and S5. For S3 and S4, stroke amplitude decreases with 448 duration for both the labials (in /papa/) and the coronals (in /tata/) cycles. Moreover, the

449 distribution of amplitude vs. duration tends to follow the theoretical curve corresponding to an 450 acceleration of $0.25 \mathrm{~g}$. On the contrary, amplitude does not decrease with duration for S1, S2 and

451 S5. Moreover, while S1 keeps a small amplitude for all durations, rate increase leads S2 and S5

452 beyond the $0.25 \mathrm{~g}$ limit curve, towards an acceleration up to $0.5 \mathrm{~g}$. Therefore, to support rate

453 increase, speakers either decrease the jaw stroke amplitude without increasing acceleration (S3

454 and S4) or increase acceleration without changing amplitude (S1, S2 and S5). These results agree 455 with the study by Sonoda and Nakakido (1986). These authors observed that jaw motion speeding 456 induced either an increase in velocity and little change in amplitude or little velocity change and a 457 decrease in amplitude (see also Lindblom, 1990a for a link with phonetic variations; and Perkell 458 et al. 2002 for a more detailed discussion of intersubject differences).

463 is a global decrease of amplitude with duration (Figure 8, right) and the distributions more or less

464 follow the $0.25 \mathrm{~g}$ curve. Furthermore, the means of amplitude and duration tend to be smaller for 465 the strokes that subtend the labial constrictions as compared to the strokes that subtend the 466 coronal constrictions, with significantly negative differences in a number of cases, and no 467 significantly positive difference (Table IV). This pattern is modulated by two factors. Firstly, 
468 there are individual differences, with, for example, larger differences between the labial and

469 coronal jaw strokes for speaker S3, and smaller for speaker S2. Secondly, the labial to coronal

470 difference is increased for /pasa/ and /sapa/ logatoms (for which the labial jaw cycle is of a

471 significantly lower amplitude and duration for all speakers) and decreased for /fata/ and /tafa/

472 logatoms (for which the difference is significant only for Speaker 3). This portrait suggests that in

473 the acceleration phase, the passage from two jaw cycles to a single one rather corresponds to a

474 progressive removal of the "labial cycle", as displayed in Figure 4. We shall now explore how the

475 reorganization between jaw, tongue and lips occurs in the "splitting" phase.

476

Table IV ----

478

3.2.4. Coordination between jaw and constrictors in the acceleration, splitting and deceleration phases

For most of the productions realized on two jaw cycles (during the acceleration and the

482 deceleration phases), the TT and LL constrictions are around $0 \%$ of the jaw trajectory (Figure 9, 483 top and bottom). This indicates that each constriction occurs when the mandible is at its highest 484 position. So, TT and LL successively move in phase with the jaw. Yet, distributions look less 485 peaked at 0\% for TT (Figure 9, right top and bottom) than for LL (Figure 9, left top and bottom) 486 for both duplicated and $\mathrm{L}_{\mathrm{a}} \mathrm{C}_{\mathrm{o}} / \mathrm{C}_{\mathrm{o}} \mathrm{L}_{\mathrm{a}}$ groups. Moreover, for $\mathrm{L}_{\mathrm{a}} \mathrm{C}_{\mathrm{o}}$ and $\mathrm{C}_{\mathrm{o}} \mathrm{L}_{\mathrm{a}}$ logatoms, there was 487 some trend for more variations during the deceleration phase than during the acceleration phase. 488 This could be interpreted as a sign of hysteresis, considering the much more complex portrait in 489 the splitting phase. 
491 cycle. The basic trend for reorganization is clearly displayed in Figure 9: the tongue constriction

492 is around the highest jaw position (phase 0\%), while the labial constriction is around the lowest

493 position (phase $50 \%$ or $-50 \%$ ). On this basic pattern, a global shift towards the right of the jaw

494 cycle can appear, with a coronal constriction in the beginning of the opening phase (around 25\%)

495 and a labial constriction in the beginning of the closing phase (around $-25 \%$ ). Two factors seem

496 to intervene in this possible shift. The first factor is speaker variability, with S2 more involved in

497 the right shift than all other speakers. The second factor is the nature of the labial and coronal

498 consonants. Thus, for /pasa/ and /sapa/, the coronal constriction is strictly located around the jaw

499 highest position ( $0 \%$ phase) while for /fata/ and /tafa/ it is often shifted towards positive values.

500 The correspondence with the predominance of the coronal jaw cycle upon the labial one in terms

501 of amplitude and duration, displayed in the previous section, is obvious. It is rather

502 straightforward. Indeed, the coronal fricative /s/ induces a specifically high jaw position,

503 generally higher than all other phonemes, including the coronal plosive /t/ or /d/ (Keating, 1983;

504 Lindblom, 1983; Keating et al., 1994; Lindblad and Lundquist, 1999, see also data for French in

505 Rhardisse and Abry, 1994). Hence the coronal jaw cycle is increased, and the coronal constriction

506 is more strictly stuck on the highest jaw value. On the contrary, the labiodental /f/, also inducing

507 a high jaw position, increases the labial jaw cycle, which induces the shift towards the right, with

508 higher values of the labial constriction in the jaw trajectory. This global pattern is also modulated

509 by the difference between $\mathrm{L}_{\mathrm{a}} \mathrm{C}_{\mathrm{o}}$ and $\mathrm{C}_{\mathrm{o}} \mathrm{L}_{\mathrm{a}}$ attractors.

510 


\subsubsection{Articulatory characterization of $L_{a} C_{o}$ and $C_{o} L_{a}$ attractors}

$\mathrm{L}_{\mathrm{a}} \mathrm{C}_{\mathrm{o}}$ utterances should be characterized by both a higher intensity of the second vowel

515 over the first one (positive value of $\Delta \mathrm{I}$, Table III) and a proximity of the labial and next coronal

516 constrictions $\left(\Delta_{(\mathrm{LaCo} / \mathrm{LaLa})}\right.$ smaller than $50 \%$, Table V). Notice however that data selection for

517 these two analyses satisfy different criteria, that is utterance duration less than $300 \mathrm{~ms}$ for the

518 acoustic analysis and utterances produced on a single jaw cycle for the articulatory analysis.

519 Despite these differences, the two analyses are relatively coherent.

520 Indeed, means of $\Delta_{(\mathrm{LaCo} / \mathrm{LaLa})}$ tend to be higher than $50 \%$ for $\mathrm{S} 1$, which agrees with the

$521 \mathrm{C}_{\mathrm{o}} \mathrm{L}_{\mathrm{a}}$ profile that characterizes this speaker in the acoustic space. On the contrary, all $\Delta_{(\mathrm{LaCo} / \mathrm{LaLa})}$ 522 means for S2 are smaller than $50 \%$, which confirms the speaker's tendency to be $\mathrm{L}_{\mathrm{a}} \mathrm{C}_{\mathrm{o}}$-stable. For $523 \mathrm{~S} 4$, means of $\Delta_{(\mathrm{LaCo} / \mathrm{LaLa})}$ are smaller than $50 \%$ for all $\mathrm{L}_{\mathrm{a}} \mathrm{C}_{\mathrm{o}}$ sequences whereas they are greater 524 than $50 \%$ for /sapa/ and /tafa/, which agrees with acoustic data showing that this speaker tends to 525 be $\mathrm{L}_{\mathrm{a}} \mathrm{C}_{\mathrm{o}}$-stable for the $\mathrm{L}_{\mathrm{a}} \mathrm{C}_{\mathrm{o}}$ logatoms and $\mathrm{C}_{\mathrm{o}} \mathrm{L}_{\mathrm{a}}$-stable for the $\mathrm{C}_{\mathrm{o}} \mathrm{L}_{\mathrm{a}}$ ones. For $\mathrm{S} 5, \Delta_{(\mathrm{LaCo} / \mathrm{LaLa})}$ 526 means are smaller than $50 \%$ for all the sequences except /pasa/ and /sapa/, which confirms his 527 acoustic profile: $\mathrm{L}_{\mathrm{a}} \mathrm{C}_{\mathrm{o}}$ for /pata/, /tapa/, /fata/ and /tafa/ but rather $\mathrm{C}_{0} \mathrm{~L}_{\mathrm{a}}$ for /sapa/. Finally, results 528 for S3 show that though this speaker does not often reach utterance durations shorter than $300 \mathrm{~ms}$

529 (Table III), she evolves towards a single jaw cycle for all sequences. Moreover, she tends to be $530 \mathrm{~L}_{\mathrm{a}} \mathrm{C}_{\mathrm{o}}$-stable with $\Delta_{(\mathrm{LaCo} / \mathrm{LaLa})}$ values always significantly smaller than $50 \%$ except for $/ \mathrm{fata} /$. 
534 Therefore, quite logically the $\mathrm{L}_{\mathrm{a}} \mathrm{C}_{\mathrm{o}}$ attractor corresponds to a decrease of the temporal 535 distance between the labial and the next coronal constriction, while the $\mathrm{C}_{\mathrm{o}} \mathrm{L}_{\mathrm{a}}$ attractor corresponds

536 to a decrease of the temporal distance between the coronal and the next labial constriction.

537 However, there is a clear predominance of switches towards the $\mathrm{L}_{\mathrm{a}} \mathrm{C}_{\mathrm{o}}$ attractor (e.g. /patá/ or /ptá/)

538 over the 21 speakers of the acoustic study (Experiment 1). This agrees with the hypothesis

539 according to which the anticipation of the tongue gesture during the labial constriction, typical of

$540 \quad \mathrm{~L}_{\mathrm{a}} \mathrm{C}_{\mathrm{o}} \mathrm{CVCV}^{\prime}$ (e.g. /patá) or $\mathrm{CCV}^{\prime}$ (e.g. /ptá/) sequences, is much more likely than the anticipation

541 of the labial gesture during the tongue constriction.

\section{Discussion}

543 The present work aimed at testing the hypothesis that the $\mathrm{L}_{\mathrm{a}} \mathrm{C}_{\mathrm{o}}$ sequencing is a more

544 stable articulatory pattern than the $\mathrm{C}_{\mathrm{o}} \mathrm{L}_{\mathrm{a}}$ one. The results of Experiment 1 provide arguments for

545 this hypothesis for French. Furthermore, the results of Experiment 2 allow to better describe the 546 articulatory phenomena that subtend this asymmetry.

The results of the articulatory study confirm that rate increase could induce the repetition

549 of $\mathrm{L}_{\mathrm{a}} \mathrm{C}_{\mathrm{o}}$ and $\mathrm{C}_{\mathrm{o}} \mathrm{L}_{\mathrm{a}} \mathrm{CVCV}$ sequences to evolve from one jaw cycle per syllable towards a single

550 jaw cycle for two syllables until a single CCV syllable is eventually achieved. This progression

551 seems more economic regarding jaw motion. In this process, the determination of the attractor $552\left(\mathrm{~L}_{\mathrm{a}} \mathrm{C}_{\mathrm{o}}\right.$ vs. $\left.\mathrm{C}_{\mathrm{o}} \mathrm{L}_{\mathrm{a}}\right)$ may result from the interaction of several factors. 
554 At the beginning of the repetition process, the speakers produce one jaw cycle per 555 syllable. During this period, each constriction occurs at the highest jaw position. Then, with rate 556 increase, the amplitude and the duration of the jaw strokes decrease together until reaching a 557 threshold value (near $50 \mathrm{~ms}$ for an opening or a closing gesture). Coupled with the anticipation of 558 one constriction during the previous one, this induces the shift on a single cycle. This shift rests 559 on the reorganization of the tongue-lip-jaw coordination. Globally, two coordinative patterns are 560 displayed to achieve the two constrictions on a single jaw cycle (Figure 10, right), depending on 561 the initial profile of jaw motions (Figure 10, left). Firstly, and in most of the cases, the jaw cycle 562 that carries the labial constriction becomes shorter and smaller than the jaw cycle that carries the 563 coronal constriction (Figure 10, top left). Hence, when rate increases, the labial cycle reaches the

564 threshold duration earlier than the coronal one. This induces the preservation of the phasing 565 between the jaw and the tongue tip highest positions, whereas the lower lip constriction occurs 566 during the jaw closing gesture or at the end of the opening gesture (Figure 10, top right). This is 567 typically the case for Speaker 3, and for /pasa/ and /sapa/ utterances. Secondly, when no 568 asymmetry appears between the two cycles during the acceleration phase (Figure 10, bottom left), 569 the tendency is to observe a dephasing of both TT and LL in reference to the jaw cycle. Thus, the 570 LL and TT constrictions respectively occur during the closing gesture and during the opening 571 gesture (Figure 10, bottom right). This is the trend for Speaker S2 and for /fata/ and /tafa/ 572 utterances. 
These results are interesting in the context of previous articulatory studies (Nelson et

577 al., 1984; Kelso et al., 1985; Hertrich and Ackermann, 2000), modeling works (Redford and

578 Diehl, 1999; Redford et al., 2001; Oudeyer, 2001) or theories (MacNeilage, 1998) that always

579 associated the jaw cycle to the CV syllable. Moreover, patterns of mandible motions are close to

580 data published in the literature and tend to confirm the general principle of economy of effort.

\subsubsection{Economy of effort}

Various possible indicators of economy of effort have been proposed in the literature, e.g. maximum speed or jerk that is acceleration derivative (Nelson, 1983). In their already mentioned

584 study, Nelson et al. (1984) characterized jaw strokes by the maximum acceleration compatible

585 with the observed movement, which is the indicator we used in Section 3. Furthermore, they

586 showed that during the repetition of /sa/ with rate increase, the jaw motion progressed in a way

587 that tended to minimize energy consumption. In their data, the durations of jaw opening and

588 closing strokes were never shorter than $50 \mathrm{~ms}$. Similar values appear in the present articulatory

589 study. Then, for one of their three analyzed speakers, Nelson et al. observed "a maximum in the

590 movement distance as the movement times decreased into the region of $125 \mathrm{~ms}$ ". According to

591 the authors, this "resonance" effect shows that $125 \mathrm{~ms}$ could be the most economic duration for

592 up and down jaw strokes. It would correspond to the "natural" rate of 3-4 cycles and so, 3-4

593 syllables per second. In our study (Experiment 2), durations of jaw cycles for $L_{a} C_{o}$ and $C_{o} L_{a}$

594 utterances are mainly around $225 \mathrm{~ms}$ (Figure 7), which corresponds to jaw stroke durations

595 around $112.5 \mathrm{~ms}$, close to the $125 \mathrm{~ms}$ value observed by Nelson et al. On the other hand, the

596 production of duplicated CVCV sequences at very fast rates requires to decrease the jaw cycle 
597 down to $150 \mathrm{~ms}$ and so, to stroke durations around $75 \mathrm{~ms}$, close to the saturation value.

598 Furthermore, estimation of the maximal acceleration value in Figure 8 indicates that it is

599 generally smaller for the $\mathrm{L}_{a} \mathrm{C}_{0}$ and $\mathrm{C}_{\mathrm{o}} \mathrm{L}_{\mathrm{a}}$ sequences compared to the duplicated ones. Taken

600 together, these results suggest that when rate increases, the coordination of the two constrictions

601 on a single jaw cycle might be more economic for the jaw than the alternation of two jaw cycles.

\subsubsection{Multi-determinism of a bistable system}

The results show that with rate increase, the lips-tongue-jaw system could evolve either

604 towards a $\mathrm{L}_{\mathrm{a}} \mathrm{C}_{\mathrm{o}}$ attractor (e.g. /pata/ $\rightarrow$ /patá/ $\rightarrow$ ptá/) or a $\mathrm{C}_{\mathrm{o}} \mathrm{L}_{\mathrm{a}}$ one $(\mathrm{e} . \mathrm{g}$. /pata/ $\rightarrow /$ tapá/ $\rightarrow /$ tpá/).

605 Thus, the coordinative system is bistable. Yet, according to the first study, the $\mathrm{L}_{\mathrm{a}} \mathrm{C}_{\mathrm{o}}$ attractor

606 prevails. On this basic pattern, a number of other additional factors are observed or could be

607 assumed to play a role. Firstly, the initial coordination provides a bootstrap towards the

608 corresponding attractor: the preference for the $\mathrm{L}_{\mathrm{a}} \mathrm{C}_{\mathrm{o}}$ attractor is less marked for the repetition of

$609 \mathrm{C}_{0} \mathrm{~L}_{\mathrm{a}}$ CVCV sequences as compared to $\mathrm{L}_{\mathrm{a}} \mathrm{C}_{0}$ ones. This is particularly the case for /pasa/ and

610 /sapa/, with /pasa/ more frequently evolving towards the $\mathrm{L}_{\mathrm{a}} \mathrm{C}_{\mathrm{o}}$ attractor whereas /sapa/ often

611 evolved towards the $\mathrm{C}_{0} \mathrm{~L}_{\mathrm{a}}$ one. This is likely to be due to the fact that, in spite of the instruction to

612 continue even if transformations occurred, some speakers tried to respect the initial structure and

613 even tended to reduce the speed when they perceived a shift to the reverse sequencing. Secondly,

614 the $\mathrm{C}_{0} \mathrm{~L}_{\mathrm{a}}$ attractor was more often observed for /sapa/ as compared to /tapa/ and /tafa/. The

615 difference between /sapa/ and the other $\mathrm{C}_{0} \mathrm{~L}_{\mathrm{a}}$ disyllables could rest on articulatory factors. Indeed,

616 analysis of the jaw cycles in the second experiment showed that in the acceleration phase, the

617 asymmetry between the jaw cycles that come with the labial constriction and the jaw cycles that

618 come with the coronal one are more systematic for /pasa/-/sapa/ than for the other sequences, 
619 which was interpreted in terms of the need for a specific high jaw position for achieving $/ \mathrm{s} /$. This

620 could favor the progression towards the $\mathrm{C}_{0} \mathrm{~L}_{\mathrm{a}}$ attractor for /pasa/ and /sapa/. Thirdly, inter-speaker

621 differences, which could come from specific individual patterns of coordination, lead to

622 differences in the selection of one or the other attractor, as displayed in Section 2.2.2.

623 But a number of other factors, not studied in the present work, could also intervene in the

624 selection of one or the other attractor. An obvious one is the selected language. Indeed, it is likely

625 that the $\mathrm{CCV}$ re-syllabification process observed here results from the fact that these forms are

626 possible in French and that the language stresses the last syllable of a word. Therefore, future

627 experiments should be done to assess the $\mathrm{L}_{\mathrm{a}} \mathrm{C}_{\mathrm{o}}$ greater stability in languages with other prosodic

628 behaviors or phonological constraints. Other additional experiments should also be done on the

629 role of the vowel context, the consonantal mode (e.g. voiced or nasal consonants), etc.

630 Nevertheless, in spite of all these established or potential additional factors, the $\mathrm{L}_{\mathrm{a}} \mathrm{C}_{\mathrm{o}}$ attractor is

631 globally the dominant one over all speakers and disyllables in the present study, which suggests

632 that it could indeed be the most stable and economic, at least in French.

The underlying assumption of this work is that world languages inventories might be

635 shaped by substance-based constraints such as properties of the motor control system. Thus, some

636 sequencing of syllables might be preferred because they are easier to produce in the sense that

637 they are more economic (less energy consuming) or more stable (easier to control). In this

638 framework (Liljencrants and Lindblom, 1972; Lindblom et al., 1984; Kelso., 1995; Davis et al.

639 2002), the present study brings at least two interesting contributions: (1) the production of

640 duplicated CVCV sequences may be more costly than the production of CVCV sequences that 
641 vary the constrictor from the first to the second consonant, and (2) the $\mathrm{L}_{\mathrm{a}} \mathrm{C}_{\mathrm{o}}$ sequencing seems 642 more stable than the reverse $\mathrm{C}_{0} \mathrm{~L}_{\mathrm{a}}$ one.

\subsubsection{Variegated rather than duplicated}

644 Statistical analyzes of world languages lexical inventories show that in $\mathrm{C}_{1} \mathrm{VC}_{2} \mathrm{~V}$ 645 sequences, lexicons favor associations that vary the articulation places in $\mathrm{C}_{1}$ and $\mathrm{C}_{2}$, rather than 646 those that repeat the same constriction (MacNeilage and Davis, 2000a, 2000b; Rousset 2003). 647 This means that languages prefer e.g. "pata" to "papa". Yet, duplication could, a priori, be 648 considered as simpler in terms of control, which could explain that it is the core behavior in 649 canonical babbling (MacNeilage and Davis, 2000a, 2000b). However, the articulatory data 650 obtained here lead to propose that the preference for variegated sequencing in world languages 651 could result in part from the fact that the repetition of the same constriction is more costly for the 652 jaw than the alternation of two different constrictions. Indeed, the comparison of the production 653 of $\mathrm{L}_{\mathrm{a}} \mathrm{C}_{\mathrm{o}} / \mathrm{C}_{\mathrm{o}} \mathrm{L}_{\mathrm{a}}$ and duplicated $\mathrm{CVCV}$ sequences shows that quicker production rates could be 654 achieved for $\mathrm{L}_{\mathrm{a}} \mathrm{C}_{\mathrm{o}} / \mathrm{C}_{\mathrm{o}} \mathrm{L}_{\mathrm{a}}$ sequences with less energy consumption for the jaw, since anticipation

655 allows producing $\mathrm{L}_{a} \mathrm{C}_{\mathrm{o}}$ and $\mathrm{C}_{0} \mathrm{~L}_{\mathrm{a}} \mathrm{CVCV}$ utterances on a single jaw cycle whereas it is impossible 656 for duplicated ones. Thus, without involving the extreme speeds obtained here at the end of the 657 acceleration phase, it appears that the alternation of the movement of two constrictors is probably 658 easier and more economic than the repetition of the movement of a single constrictor for the 659 mature speech production system. Similar principles govern other synergies such as fingers in 660 piano playing. This results from the fact that when two different organs are involved, the motion 661 of one organ could be anticipated during the realization of the other one, which is not possible 662 when a single organ realizes the two successive gestures. The possibility to produce two syllables 
663 on a single jaw cycle might be generalized to other kinds of sequencing than $\mathrm{L}_{\mathrm{a}} \mathrm{C}_{\mathrm{o}}$ and $\mathrm{C}_{\mathrm{o}} \mathrm{L}_{\mathrm{a}}$ ones

664 in further investigations. Moreover, the preference for the $\mathrm{L}_{\mathrm{a}} \mathrm{C}_{\mathrm{o}}$ attractor in the two experiments

665 shows that inside the preference for variegated forms, some associations might be more 666 appropriate than others.

\subsection{2. $L_{a} C_{o}$ rather than $C_{o} L_{a}$}

The results of Experiment 1 are in favor of the idea that $L_{a} C_{o}$ sequences appear as a

669 natural and coherent production unit, more stable and better "in-phase" than their $\mathrm{C}_{\mathrm{o}} \mathrm{L}_{\mathrm{a}}$ inverse

670 counterpart. This could explain the preference for $\mathrm{L}_{\mathrm{a}} \mathrm{C}_{\mathrm{o}}$ utterances in infant production, rather

671 than the "simple first" explanation previously proposed. There is actually no reason to believe 672 that the greater stability of $\mathrm{L}_{\mathrm{a}} \mathrm{C}_{\mathrm{o}}$ sequences in the present experiments on adults could be due to 673 any "simple first" mechanism. Rather, articulatory coherence could provide a common basis to

674 both infant data and our results. Of course, the fact that the $\mathrm{C}_{\mathrm{o}} \mathrm{L}_{\mathrm{a}}$ structure may also be locally 675 stable, though less often selected in the speeding process, is not incompatible with this reasoning. 676 It just suggests that $\mathrm{C}_{\mathrm{o}} \mathrm{L}_{\mathrm{a}}$ sequences are also viable, though suboptimal in comparison with $\mathrm{L}_{\mathrm{a}} \mathrm{C}_{\mathrm{o}}$ 677 ones, which agrees well with typological and developmental data.

678 5. Conclusion

679 The experimental data analyzed here point out a major difference between $\mathrm{L}_{\mathrm{a}} \mathrm{C}_{\mathrm{o}}$ and $\mathrm{C}_{\mathrm{o}} \mathrm{L}_{\mathrm{a}}$ 680 sequences at the production level: $\mathrm{L}_{\mathrm{a}} \mathrm{C}_{\mathrm{o}}$ sequences can be considered as a more stable 681 coordinative pattern for the motor system than $\mathrm{C}_{0} \mathrm{~L}_{\mathrm{a}}$ ones. Then, a causal relationship between 682 this asymmetry and the universal "LC effect" has been advanced. Of course, such a claim has to 683 be improved testing $\mathrm{L}_{\mathrm{a}} \mathrm{C}_{\mathrm{o}}$ and $\mathrm{C}_{\mathrm{o}} \mathrm{L}_{\mathrm{a}}$ sequences stability in both other languages and more directly 
684 in infant' first words. To this aim, the paradigm and the acoustic analysis method proposed here

685 could allow comparing $\mathrm{L}_{\mathrm{a}} \mathrm{C}_{\mathrm{o}}$ and $\mathrm{C}_{\mathrm{o}} \mathrm{L}_{\mathrm{a}}$ stability for speaker samples of different languages, which

686 is necessary for generalization. Specific methodologies should be developed for studying stability

687 in infant speech. Moreover, further articulatory investigations of jaw-tongue-lip coordination in 688 the production of $\mathrm{C}_{1} \mathrm{VC}_{2} \mathrm{~V}$ disyllables would be necessary to better understand the anticipation 689 processes, and their link with the asymmetry in jaw cycles for different constriction places in $\mathrm{C}_{1}$

690 and $\mathrm{C}_{2}$. It remains that the present study adds some new material to the already significant set of

691 perceptuo-motor constraints likely to play a role in the shaping of phonological systems, 692 hopefully taking substance-based approaches to language universals one step further.

\section{Acknowledgements}

This work is part of the "Patipapa" project funded by the French Ministry of Research

695 (Action Concertée Incitative "Systèmes Complexes en Sciences Humaines et Sociales"). We also

696 thank C. Savariaux and C. Vilain for their technical support and all the speakers for their essential 697 participation.

698

699 


\section{Notes}

$700 \quad{ }^{1}$ The Praat software is developed by P. Boersma and D. Weenink, at the Institute of

701 Phonetic Sciences. It is available to free download on their web page

702 (http://www.fon.hum.uva.nl/praat/).

703 


\section{References}

Byrd, D. (1996). "Influences on articulatory timing in consonant sequences," J. Phonetics, 24, 209-244.

Chitoran, I., Goldstein, L. and Byrd, D. (2002). Gestural overlap and recoverability: Atriculatory evidence from Georgian, in C. Gussenhoven \& Warner (Eds), Laboratory Phonology 7. Berlin: Mouton de Gruyter, 419-448.

Clements, G. N. (1990). "The role of the sonority cycle in core syllabication," in Papers in Laboratory Phonology 1: Between the Grammar and the Physics of Speech, edited by Kingston, J. \& Beckman, M., (Cambridge University Press), 283-333.

Davis, B.L., MacNeilage, P.F., and Matyear, C. (2002). "Acquisition of serial complexity in speech production: A comparison of phonetic and phonological approaches to first word production," Phonetica, 59, 75-107. 826-840.

Haken, H., Kelso, J. A. S. and Bunz, H. (1985). “A theoretical model of phase transitions in human hand movements," Biol. Cybern. 51, 347-356. rate-controlled syllable repetitions," J. Acoust. Soc. Am. 107, 2236-2247. 
Hoole P. (1996) "Issues in the acquisition, processing, reduction and parameterization of articulographic data," FIPKM 34, pp 158-173

Hoyt, D. and Taylor, C.R. (1981). "Gait and the Energetic of Locomotion in Horses," Nature, 292, 239-240.

Ingram, D. (1974). “Fronting in child phonology,” J. Child Lang. 1, 233-242.

Keating, P., Lindblom, B., Lubker, J., and Kreiman, J. (1994). "Variability in jaw height for segments in english and swedish VCVs," J. Phonetic, 22, 407-422.

Keating, P. (1983). "Comments on the jaw and syllable structure," J. Phonetic, 11, 401406.

Kelso., J. A. S. (1995). Dynamic patterns: The self-organization of brain and behavior. (MIT Press), Cambridge, MA.

Kelso, J. A. S., Saltzman, E. L. and Tuller, B. (1986). "The dynamical perspective on speech production: data and theory,” J. Phonetic, 14, 29-59.

Kelso, J. A. S., Vatikiotis-Bateson, E., Saltzman, E. L. and Kay, B. (1985). “A qualitative dynamic analysis of reiterant speech production: phase portraits, kinematics, and dynamic modeling,” J. Acoust. Soc. Am. 77, 266-280. systems: the role of perceptual contrast," Language, 48, 839-862.

Lindblad, P. and Lundqvist, S. (1999). "How and why do the tongue gestures of [t], [d], [1], [n], [s], and [r] differ?", in Proceedings of the 14th ICPhS, 417-420. 
Lindblom, B. (1990a). "Explaining Phonetic Variation, A Sketch of the H\&H Theory," in Speech Production and speech modeling, edited by W. J. Hardcastle \& A. Marchal, (Academic Publishers), 403-439.

Lindblom, B., (1990b). "On the notion of "possible speech sound", "J. Phonetic, 18, 135152.

Lindblom, B., MacNeilage, P.F. and Studdert-Kennedy, M. (1984). Self-organizing Processes and the Explanation of Languages Universals, in Explanations of Linguistic Universals, edited by Butterworth, B., Comrie, B., and Dahl, O., (Mouton), 181-203.

Locke, J. L. (2000). “Movement patterns in spoken language,” Science, 288, 449-451. Locke, J. L. (1983). Phonological Acquisition and Change, (Academic Press, New York). MacNeilage, P.F. (1998). "The frame/content theory of evolution of speech production," Behav. Brain Sci. 21, 499-511.

MacNeilage, P.F., Davis, B.L., Kinney, A. and Matyear, C.L. (2000a). "The motor core of speech: A comparaison of serial organizations patterns in infants and languages," Child. Dev. 71, 153-163.

MacNeilage, P.F. and Davis, B.L. (2000b). "On the origins of intenal structure of word forms," Science, 288, 527-531.

Munhall, K.G. and Jones, J.A. (1998). "Articulatory evidence for syllabic structure," Behav. Brain Sci. 21, 524-525.

Nelson, W. L. (1983). "Physical principles for economies of skilled movements," Biol. Cybern. 46, 135-147. 
Nelson, W.L., Perkell, J.L. and Westbury, J.R. (1984). "Mandibule movements during increasingly rapid articulations of single syllables : Preliminary observations," J. Acoust. Soc. Am. 75, 945-951.

Nittrouer, S. (1991). "Phase relations of jaw and tongue tip movements in the production of VCV utterances," J. Acoust. Soc. Am. 90, 1806-1815.

Ostry, D.J. and Flanagan, J.R. (1989). "Human jaw movement in mastication and speech,” Arch. Oral Biol., 34, 685-693.

Oudeyer, P-Y. (2001). "The origins of syllable systems: An operational model," in Proceedings of the Twenty-third Annual Conference of the Cognitive Science Society, edited by J. D. Moore and K. Stenning (Laurence Erlbaum Associates), 744-749.

Perkell, J. S., Zandipour, M., Matthies, M. L. and Lane, H. (2002). "Economy of effort in 776 different speaking conditions. I. A preliminary study of intersubject differences and modeling issues," J. Acoust. Soc. Am. 112, 1627-1641.

Perkell, J. S. and Zandipour, M. (2002). "Economy of effort in different speaking conditions. II. kinematic performance spaces for cyclical and speech movements," J. Acoust. Soc. Am. 112, 1642-1651.

Rhardiss, N. and Abry, C. (1994). "La coarticulation mandibulaire comme principe d'organisation syllabique (Et si la mandibule syllabisait ALIS?)," in Proceedings of the XXèmes Journée d'Etude sur la Parole, Trégastel, 421-426. universals and variation in syllable systems," Language and Speech, 44, 27-56. 
Redford, M.A. and Diehl, R.L. (1999). “The relative perceptual distinctiveness of initial and final consonants in cve syllables," J. Acoust. Soc. Am. 103, 1555-1565.

Rousset, I. (2003). "From lexical to syllabic organization: favored and disfavored cooccurrences," In Proceedings of the 15th ICPhS (Barcelona, Spain), 715-718. "Multistable syllables as enacted percepts: a source of an asymmetric bias in the verbal transformation effect," Perception \& Psychophysics, 68 (3), 458-474.

Selkirk, E. (1984). On the major class features and syllable theory (MIT Press). Vowel Sequence” J. Acoust. Soc. Jpn (E) 7, 5-12.

Stevens, K. N. (1989). “On the Quantal Nature of Speech,” J. Phonetics, 17, 3 - 45. Acoust. Soc. Am., 104 (1), 518-529.

Tuller, B. and Kelso, J. A. S. (1991). "The production and perception of syllable structure,” J. Speech Hear. Res. 34, 501-508.

Vilain, A., Abry, C., Badin, P. and Brosda, S. (1999). "From idiosyncratic pure frame to variegated babbling: evidence from articulatory modelling," in Prodeedings of ICPhS'99 (San Fransisco, USA), 2497-2500. 
807 Tables

808 
809 Table I: Analysis of intensity variations between the vowel after the labial and the

810 vowel after the coronal consonant for utterances shorter than $300 \mathrm{~ms}$ for the 42 analyzed

811 trials (see text for the details about data selection). For each disyllable: means (dB) and

812 are compared with 0 according to a two-tails t-test $(d f=41)$ with Bonferroni correction

$813 \quad(* p \leq .01 / 6) ;$ standard errors; repartition of the 42 means according to their sign: for all

814 the means and for the means that significantly differ from 0 according to a two-tails t-test

815 with Bonferroni correction $(p \leq .05 / 42)$.

\begin{tabular}{ll|cccccc} 
& & pata & tapa & pasa & sapa & fata & tafa \\
\hline Means & & $6.6 *$ & $7.0 *$ & $7.5^{*}$ & 3.8 & $8.9 *$ & 8.6 * \\
\hline Standard errors & & 1.9 & 1.9 & 1.7 & 1.7 & 1.7 & 2.1 \\
\hline Number of positive & All & 30 & 30 & 27 & 21 & 37 & 33 \\
means & Signif. & 19 & 15 & 18 & 13 & 26 & 21 \\
\hline $\begin{array}{l}\text { Number of negative } \\
\text { means }\end{array}$ & All & 12 & 12 & 15 & 21 & 5 & 9 \\
& Signif. & 4 & 6 & 6 & 9 & 2 & 4
\end{tabular}

816 
817 Tableau II: Number of CVCV or CCV utterances correctly produced (Tot.) and number of

818 utterances produced with sufficient jaw motion (see text) and kept for further articulatory

819 analysis (Ar.) for each speaker and each sequence.

820

\begin{tabular}{l|ll|ll|ll|ll|l|l|l|ll|ll|l|l}
\multicolumn{2}{|c|}{} & \multicolumn{2}{c|}{ papa } & \multicolumn{2}{c|}{ tata } & \multicolumn{2}{c|}{ pata } & \multicolumn{2}{c|}{ tapa } & \multicolumn{2}{c|}{ pasa } & \multicolumn{2}{c|}{ sapa } & \multicolumn{2}{c|}{ fata } & \multicolumn{2}{c}{ tafa } \\
\hline & Tot. & Ar. & Tot. & Ar. & Tot. & Ar. & Tot. & Ar. & Tot. & Ar. & Tot. & Ar. & Tot. & Ar. & Tot. & Ar. \\
S1 & 63 & 63 & 63 & 60 & 61 & 59 & 59 & 54 & 60 & 59 & 54 & 54 & 53 & 51 & 51 & 47 \\
S2 & 51 & 49 & 53 & 52 & 58 & 47 & 52 & 48 & 62 & 43 & 59 & 43 & 65 & 59 & 58 & 49 \\
S3 & 53 & 51 & 56 & 54 & 60 & 59 & 63 & 61 & 59 & 59 & 64 & 64 & 57 & 57 & 65 & 65 \\
S4 & 66 & 63 & 68 & 60 & 76 & 52 & 73 & 55 & 74 & 73 & 62 & 60 & 69 & 64 & 71 & 53 \\
S5 & 94 & 85 & 100 & 76 & 109 & 93 & 102 & 80 & 99 & 73 & 95 & 82 & 98 & 79 & 100 & 74
\end{tabular}


821 and the vowel after the labial consonant for utterances shorter than $300 \mathrm{~ms}$ for the three

822 trials taken together, for each speaker and each disyllable ( $n$ is the number of observations

823 for $m$ computation). Thirty t-tests $(d f=n$-1) with Bonferroni correction compare each

824 mean to $0\left({ }^{\circ} p \leq .005, * p \leq .05 / 30, * * p \leq .01 / 30\right)$.

825

\begin{tabular}{|c|c|c|c|c|c|c|c|c|c|c|c|c|}
\hline & \multicolumn{2}{|c|}{ pata } & \multicolumn{2}{|c|}{ tapa } & \multicolumn{2}{|c|}{ pasa } & \multicolumn{2}{|c|}{ sapa } & \multicolumn{2}{|c|}{ fata } & \multicolumn{2}{|c|}{ tafa } \\
\hline & $n$ & $\mathrm{~m}$ & $\mathrm{n}$ & $\mathrm{m}$ & $n$ & $\mathrm{~m}$ & $\mathrm{n}$ & $\mathrm{m}$ & $n$ & $\mathrm{~m}$ & $n$ & $\mathrm{~m}$ \\
\hline S1 & 31 & 0.8 & 29 & -0.1 & 29 & $-1.4^{*}$ & 27 & $-2.9^{* *}$ & 23 & -0.2 & 24 & -0.7 \\
\hline S2 & 25 & $23.2^{* *}$ & 11 & 9.2 & 25 & $11.7^{*}$ & 20 & 5.5 & 30 & $20.3^{* *}$ & 20 & $13.9^{* *}$ \\
\hline S3 & 5 & -0.8 & 9 & -0.7 & 0 & - & 0 & - & 0 & - & 10 & 1.5 \\
\hline S4 & 43 & -0.7 & 37 & $-4.7^{\circ}$ & 37 & -0.1 & 30 & $-2.4^{* *}$ & 28 & 0.3 & 29 & $-1.6^{\circ}$ \\
\hline S5 & 67 & $6.9^{* \star}$ & 59 & $4.7^{\star \star}$ & 56 & $1.7^{\circ}$ & 45 & $-2.5^{\star *}$ & 54 & $7.6^{\star *}$ & 53 & 1.1 \\
\hline
\end{tabular}

826

827

828 
829 the labial and the coronal constrictions in the acceleration phase, for each speaker and

830 each $L_{a} C_{o} / C_{o} L_{a}$ pair (n is the number of observations for means computations). The

831 significance of the difference between means was tested using t-tests $(d f=n$-1) with

832 Bonferroni corrections $\left({ }^{* *} p \leq .01 / 15, * p \leq .05 / 15\right.$, NS : Not Significant).

833

\begin{tabular}{c|c|c|ccc|ccc|} 
& & & \multicolumn{3}{|c|}{ Amplitudes $(\mathbf{m m})$} & \multicolumn{3}{c|}{ Durations (ms) } \\
Speaker & Sequence & $\mathbf{n}$ & labial & coronal & $\mathbf{p}$ & labial & coronal & $\mathbf{p}$ \\
\hline \multirow{2}{*}{$\mathbf{s 1}$} & pata/tapa & 47 & 0,58 & 0,91 & $* *$ & 163,6 & 198,6 & $* *$ \\
& pasa/sapa & 38 & 0,59 & 2,06 & $* *$ & 162,7 & 247,2 & $* *$ \\
& fata/tafa & 23 & 0,98 & 0,77 & $\mathrm{NS}$ & 272,6 & 222,1 & $\mathrm{NS}$ \\
\hline \multirow{2}{*}{$\mathbf{s 2}$} & pata/tapa & 21 & 1,83 & 1,57 & $\mathrm{NS}$ & 231,9 & 244,0 & $\mathrm{NS}$ \\
& pasa/sapa & 28 & 1,07 & 1,48 & $* *$ & 209,1 & 285,2 & $* *$ \\
& fata/tafa & 23 & 1,00 & 0,83 & $\mathrm{NS}$ & 263,7 & 235,7 & $\mathrm{NS}$ \\
\hline \multirow{2}{*}{$\mathbf{s 3}$} & pata/tapa & 59 & 1,17 & 2,75 & $* *$ & 178,3 & 229,7 & $* *$ \\
& pasa/sapa & 55 & 1,01 & 3,46 & $* *$ & 169,9 & 269,5 & $* *$ \\
& fata/tafa & 54 & 2,02 & 2,36 & $* *$ & 211,2 & 219,5 & $\mathrm{NS}$ \\
\hline \multirow{2}{*}{$\mathbf{s 4}$} & pata/tapa & 23 & 1,16 & 2,67 & $* *$ & 174,7 & 247,0 & $* *$ \\
& pasa/sapa & 18 & 1,20 & 3,89 & $* *$ & 206,1 & 279,2 & $\mathrm{NS}$ \\
& fata/tafa & 33 & 1,57 & 1,34 & $\mathrm{NS}$ & 223,3 & 214,6 & $\mathrm{NS}$ \\
\hline \multirow{2}{*}{$\mathbf{s 5}$} & pata/tapa & 35 & 0,85 & 2,53 & $* *$ & 204,7 & 268,0 & $*$ \\
& pasa/sapa & 14 & 1,08 & 3,78 & $* *$ & 196,0 & 370,7 & $*$ \\
& fata/tafa & 52 & 1,43 & 1,66 & $\mathrm{NS}$ & 267,8 & 247,0 & $\mathrm{NS}$
\end{tabular}


835 utterance duration $\Delta\left(L_{a} C_{o} / L_{a} L_{a}\right)$, expressed in percent, for each speaker and each disyllable

836 ( $n$ is the number of utterances involved in computing $m$ ). Values smaller than 50\% indicate

837 that the duration from the labial constriction to the following coronal one is smaller than

838 the duration from the coronal constriction to the following labial one, which signals an

839 evolution towards the $L_{a} C_{o}$ attractor. On the contrary, values higher than $50 \%$ signal an

840 evolution towards the $C_{o} L_{a}$ attractor. Thirty two-tails t-tests $(d f=n$-1) with Bonferroni

841 correction compare each mean to $50(* p<=.05 / 30, * * p<=.01 / 30)$.

842

843

\begin{tabular}{c|cc|cc|cc|cc|cc|cc} 
& \multicolumn{2}{|c|}{ pata } & \multicolumn{2}{c|}{ tapa } & \multicolumn{2}{c|}{ pasa } & \multicolumn{2}{c|}{ sapa } & \multicolumn{2}{c|}{ fata } & \multicolumn{2}{c}{ tafa } \\
\hline & $\mathrm{n}$ & $\mathrm{m}$ & $\mathrm{n}$ & $\mathrm{m}$ & $\mathrm{n}$ & $\mathrm{m}$ & $\mathrm{n}$ & $\mathrm{m}$ & $\mathrm{n}$ & $\mathrm{m}$ & $\mathrm{n}$ & $\mathrm{m}$ \\
S1 & 20 & 49,3 & 5 & 53,0 & 27 & 50,8 & 26 & 51,0 & 31 & $53,7^{* *}$ & 32 & 52,0 \\
S2 & 25 & $36,3^{* *}$ & 21 & $40,3^{*}$ & 20 & 41,1 & 22 & 43,9 & 40 & $30,5^{* *}$ & 36 & $36,1^{* *}$ \\
S3 & 19 & $44,3^{*}$ & 11 & $38,6^{* *}$ & 22 & $41,5^{* *}$ & 17 & $42,5^{* *}$ & 10 & 44,8 & 23 & $43,7^{* *}$ \\
S4 & 56 & $45,4^{*}$ & 48 & 49,5 & 60 & $46,3^{* *}$ & 44 & 52,0 & 38 & $42,8^{* *}$ & 30 & 51,4 \\
S5 & 67 & $42,1^{* *}$ & 58 & $40,8^{* *}$ & 67 & 51,8 & 71 & $53,5^{*}$ & 35 & $37,9^{* *}$ & 41 & $44,9^{*}$
\end{tabular}

844

845

846 


\section{List of figures}

847 Figure 1: Labeling of intensity curves and measurements: intensity curves (bottom) of the acoustic signal (top)

848 against time for three samples of a /tapa/trial. The repetition progressively evolves from /tapa/(left) towards /tápa/

849 (middle) until /ptá/ (right). $L_{a}$ and $C_{o}$ are the labial and coronal consonants; $V_{\text {La }}$ and $V_{C o}$ are the vowels respectively

850 following $L_{a}$ and $C_{o}$. This labeling allows computing the duration of an utterance and the intensity variation of

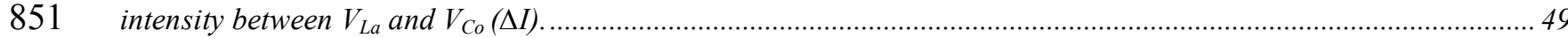

852 Figure 2: Intensity variation between the vowel after the labial constriction and the vowel after the coronal

853 constriction ( $\triangle I$ ) plotted against duration for /pasa/ (left) and /sapa/ (right) CVCV and CCV correctly produced

854 utterances for all subjects (top). Results for /pasa/ and /sapa/ are representative of the two other $L_{a} C_{o}$ (/pata/, /fata/)

855 and $C_{o} L_{a}$ (/tapa/, /tafa/) pairs. Bottom: Standard deviations of $\Delta$ I against utterances durations (100 ms meantime)

856 for the 6 CVCV sequences. Dispersion increases when duration becomes shorter than $300 \mathrm{~ms}$

857 Figure 3: Attractor stability and speakers' profiles. On the left: $\Delta$ I mean (variation of intensity between the vowel

858 after the labial consonant and the vowel after the coronal consonant) of the second trial against $\Delta I$ mean of the first

859 trial for each CVCV and each speaker when the two means significantly differ from zero (two-tails Student test with

860 Bonferroni correction $p \leq .05 / 42$ ). Points inside the top left and the bottom right squares correspond to cases with

861 attractor shift from one trial to the other. Points inside the top right and bottom left squares respectively represent

$862 L_{a} C_{o}$ and $C_{o} L_{a}$ stability for the two trials. On the right: $\triangle I$ means for the two selected trials for each CVCV offour

863 typical speakers with $S 20$ and $S 6$ as bi-stable profiles; $S 12$ as $L_{a} C_{o}$ stable and $S 23$ as $C_{o} L_{a}$ stable. The convex hulls of

$864 S 23, S 20$ and S12 are displayed on the figure on the left (* : mean significantly different from zero, $p \leq .05 / 42) . . . .51$

865 Figure 4: Acoustic signal, jaw, Tongue Tip (TT) and Lower Lip (LL) displacements against time for samples of a

866 Itapa/ trial (S3). From left to right: sample of the acceleration phase; sample of the period with one jaw cycle for two

867 syllables (splitting) and sample of the deceleration phase. The arrows on trajectory curves represent the labeled

868 minima and maxima for the jaw and the maxima for the constrictors. Notice the secondary maxima for TT and LL

869 due to passive motion induced by the jaw gesture that comes with the other constriction (these secondary maxima

870 are not incorporated in further analyses in Experiment 2) 
871 Figure 5: Articulatory measurements. A: duration and amplitude of the jaw cycle are respectively the sum of its up

872 and down stroke durations and the mean of its up and down stroke amplitudes. B: position of the Tongue Tip (P(TT))

873 and of the Lower Lip $(P(L L))$; constriction events were displayed on the jaw cycle normalized between -50\% and

$87450 \%$ with $-50 \%$ at the beginning of the up stroke, $0 \%$ at the jaw maxima and $50 \%$ at the end of the down stroke..... 53

875 Figure 6: Intensity variation between the vowel after the labial constriction and the vowel after the coronal

876 constriction ( $\Delta I)$ against utterance duration for all subjects' duplicated (left) and $L_{a} C_{o}-C_{o} L_{a}($ right) productions. $\Delta I$

877 does not vary much with duration for duplicated logatoms whereas duration around 300 ms (vertical doted line)

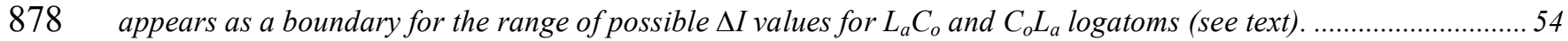

879 Figure 7: First row: Jaw cycle durations against utterance durations for all speakers' productions and separately

880 for duplicated (left) and $L_{a} C_{o} / C_{o} L_{a}$ sequences (right). Distribution splitting observed for the $L_{a} C_{o}$ and $C_{o} L_{a}$ groups

881 shows that these disyllables could be produced on a single jaw cycle whereas duplicated disyllables are always

882 realized on two jaw cycles. Second and third rows: distribution of utterance and jaw cycle durations for all speakers'

883 productions. The utterance durations tend to be shorter for the $L_{a} C_{o} / C_{o} L_{a}$ group as compared to the duplicated one

884 whereas the contrary tends to appear for the jaw cycle durations 55

885 Figure 8: Jaw strokes amplitude (up and down) against duration during the acceleration phase (when the disyllables 886 are realized with two jaw cycles) for each speaker and separately for duplicated (left column) and $L_{a} C_{o} / C_{o} L_{a}($ right 887 column) disyllables. The parabolic curves are the theoretical minimum-time boundaries for mandible movements for 888 three control acceleration limits (from left to right: $1.5 \mathrm{~g}, 0.5 \mathrm{~g}$ and $0.25 \mathrm{~g}$, (see Nelson 1983)). Regression lines and 889 distribution means (squares and circles) are displayed separately for jaw strokes that come with labials and with 890 coronals (see text for details) 56

891 Figure 9: Distribution of speakers' productions according to the position of the Lower-Lip (left) and the Tongue-Tip

892 (right) constrictions relative to the jaw cycle. The three phases (acceleration, splitting and deceleration) are plotted

893 separately. For the acceleration and the deceleration phases, histograms include all speakers taken together and

894 both duplicated and $L_{a} C_{o} / C_{o} L_{a}$ sequences. For the splitting phase (when utterances are realized on a single jaw

895 cycle), distributions are given for each $L_{a} C_{o}$ and $C_{o} L_{a}$ sequence and for each speaker. 57

896 Figure 10: Coordination between the jaw and the constrictors from two jaw cycles for a disyllable to a single one.

897 Two patterns (A and B) of lower lip (LL) and tongue tip (TT) constriction positions relative to the jaw cycle are 
898 observed when the two plosives are realized on a single jaw cycle (splitting, right). They tend to correspond to

899 specific jaw motion profiles during the acceleration phase (left, see text for detail).............................................. 58

900 
900 Figures

901 


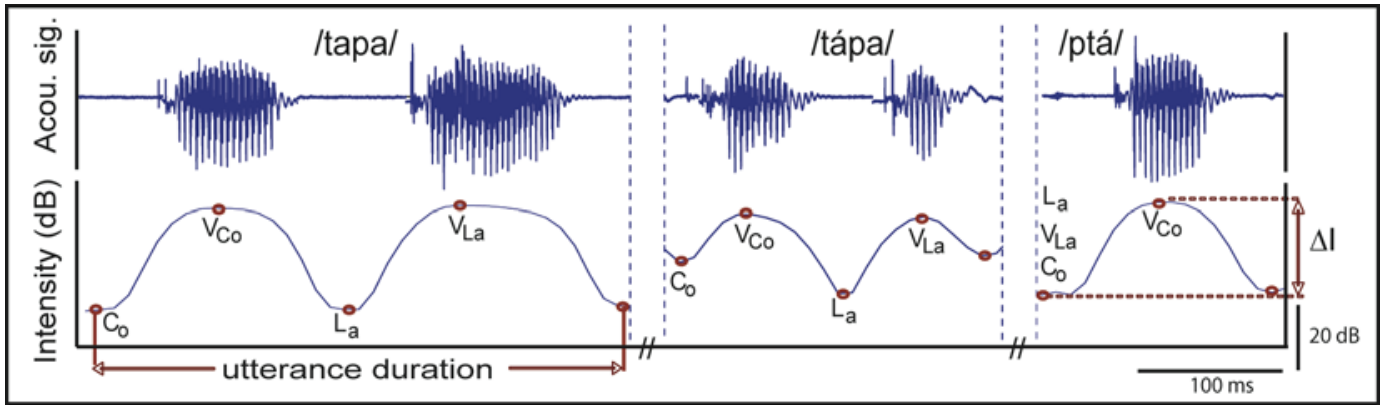

902 Figure 1: Labeling of intensity curves and measurements: intensity curves (bottom) of the

903 acoustic signal (top) against time for three samples of a /tapa/ trial. The repetition

904 progressively evolves from /tapa/ (left) towards /tápa/ (middle) until /ptá/ (right). $L_{a}$ and $C_{o}$

905 are the labial and coronal consonants; $V_{L a}$ and $V_{C o}$ are the vowels respectively following $L_{a}$

906 and $C_{o}$. This labeling allows computing the duration of an utterance and the intensity

907 variation of intensity between $V_{L a}$ and $V_{C o}(\Delta I)$.

908 


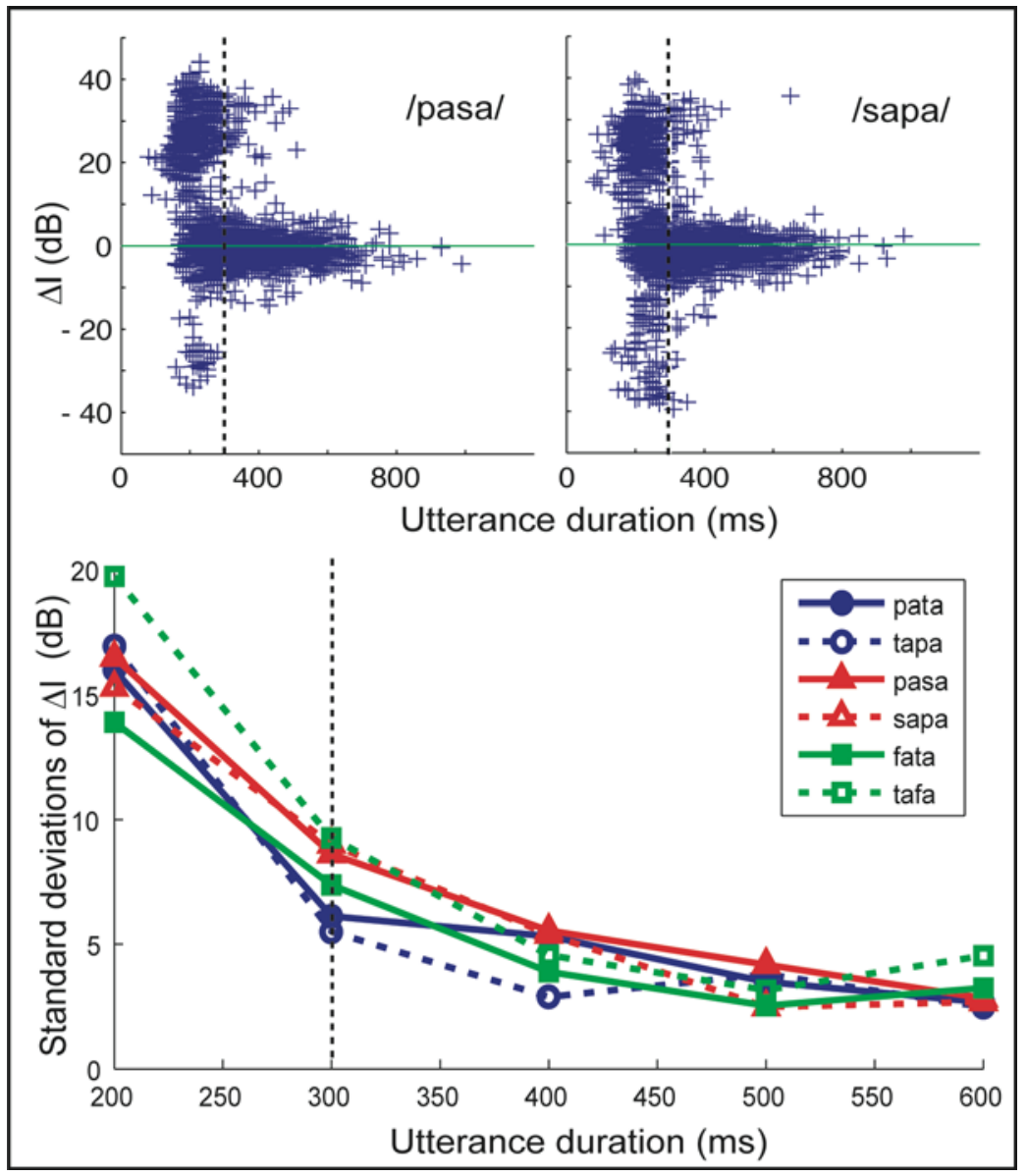

909 Figure 2: Intensity variation between the vowel after the labial constriction and the vowel

910 after the coronal constriction ( $\Delta I)$ plotted against duration for /pasa/ (left) and /sapa/ (right)

911 CVCV and CCV correctly produced utterances for all subjects (top). Results for /pasa/ and

912 /sapa/ are representative of the two other $L_{a} C_{o}$ (/pata/, /fata/) and $C_{o} L_{a}$ (/tapa/, /tafa/) pairs.

913 Bottom: Standard deviations of $\Delta I$ against utterances durations (100 ms meantime) for the 6

914 CVCV sequences. Dispersion increases when duration becomes shorter than 300 ms. 


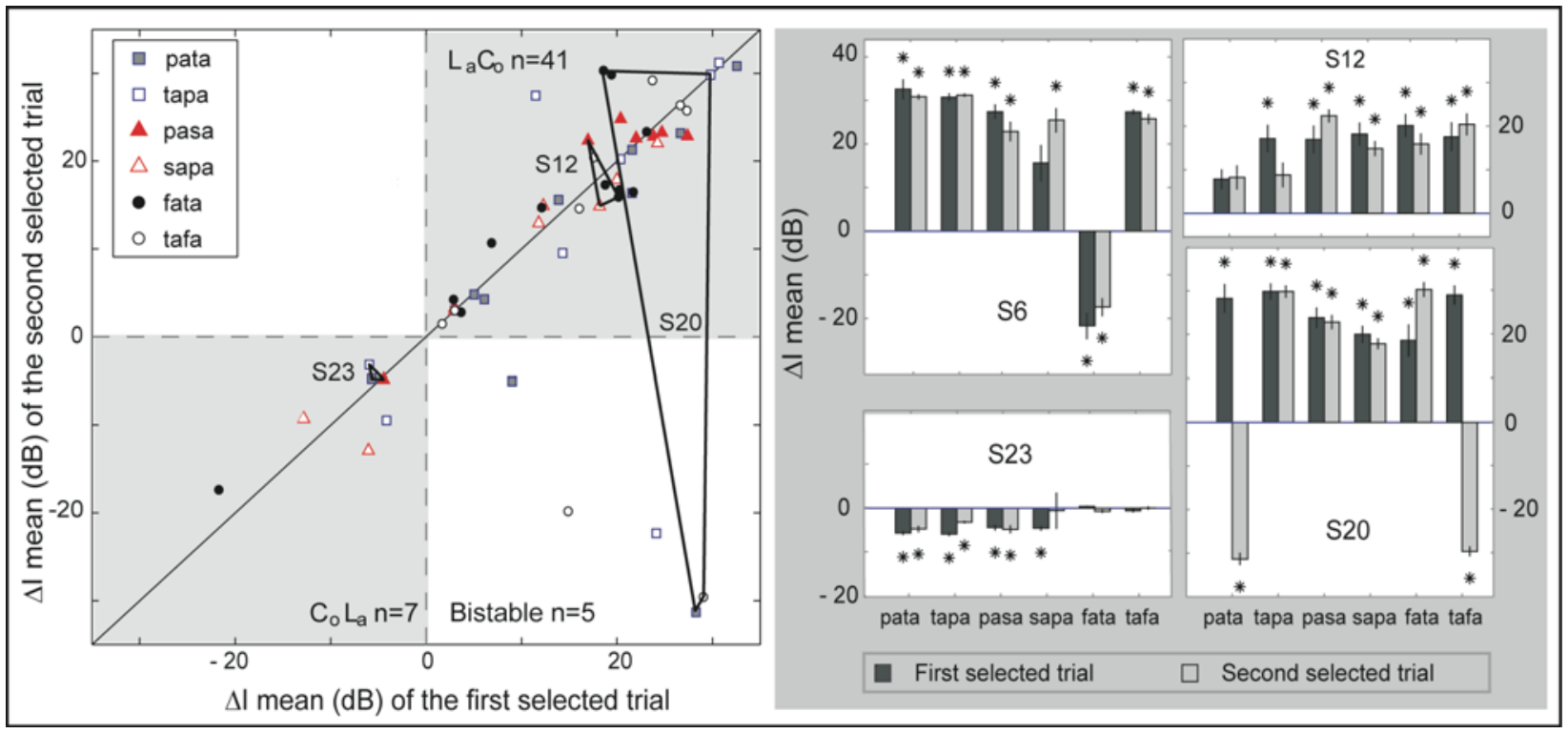

918 Figure 3: Attractor stability and speakers' profiles. On the left: $\Delta I$ mean (variation of

919 intensity between the vowel after the labial consonant and the vowel after the coronal

920 consonant) of the second trial against $\triangle I$ mean of the first trial for each CVCV and each

921 speaker when the two means significantly differ from zero (two-tails Student test with

922 Bonferroni correction $p \leq .05 / 42$ ). Points inside the top left and the bottom right squares

923 correspond to cases with attractor shift from one trial to the other. Points inside the top

924 right and bottom left squares respectively represent $L_{a} C_{o}$ and $C_{o} L_{a}$ stability for the two

925 trials. On the right: $\triangle I$ means for the two selected trials for each CVCV of four typical

926 speakers with $S 20$ and $S 6$ as bi-stable profiles; $S 12$ as $L_{a} C_{o}$ stable and $S 23$ as $C_{o} L_{a}$ stable.

927 The convex hulls of S23, S20 and S12 are displayed on the figure on the left (*: mean

928 significantly different from zero, $p \leq .05 / 42)$. 


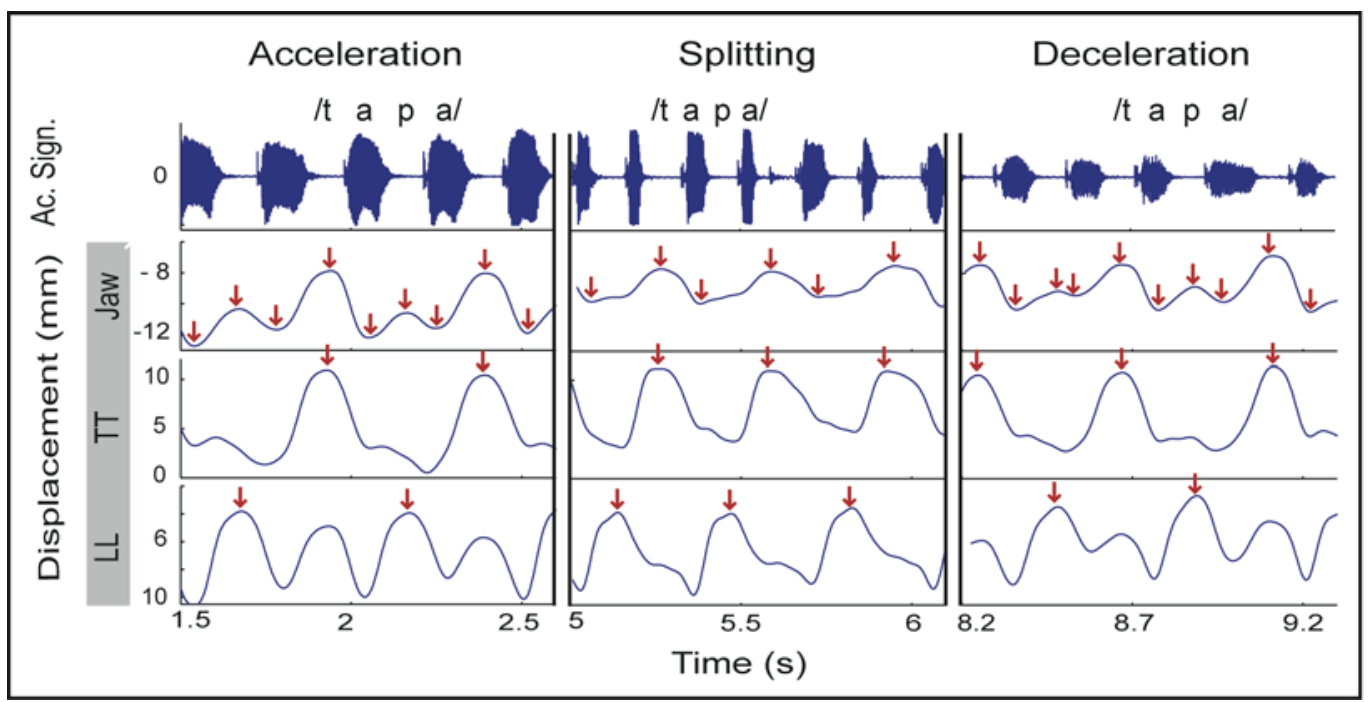

$930 \quad$ Figure 4: Acoustic signal, jaw, Tongue Tip (TT) and Lower Lip (LL) displacements against

931 time for samples of a /tapa/ trial (S3). From left to right: sample of the acceleration phase;

932 sample of the period with one jaw cycle for two syllables (splitting) and sample of the

933 deceleration phase. The arrows on trajectory curves represent the labeled minima and

934 maxima for the jaw and the maxima for the constrictors. Notice the secondary maxima for

935 TT and LL due to passive motion induced by the jaw gesture that comes with the other

936 constriction (these secondary maxima are not incorporated in further analyses in

937 Experiment 2). 

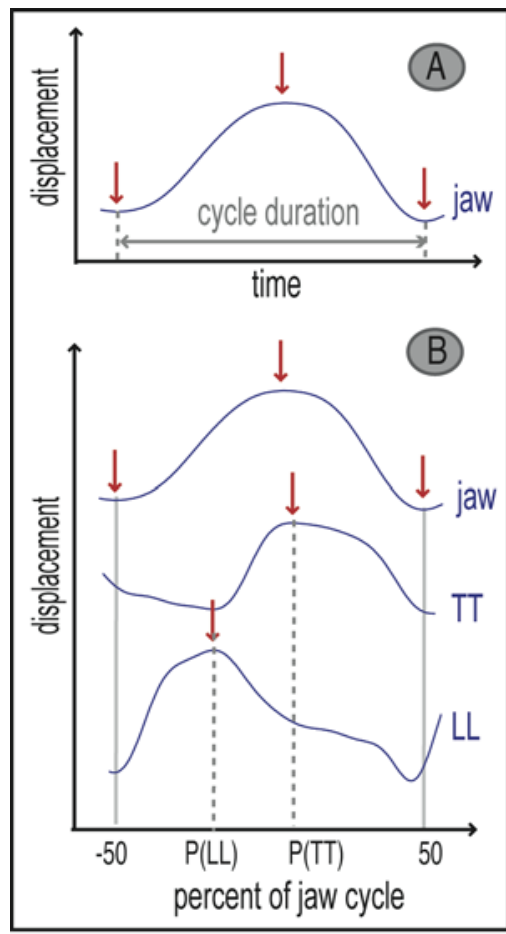

$940 \quad$ Figure 5: Articulatory measurements. A: duration and amplitude of the jaw cycle are 941 respectively the sum of its up and down stroke durations and the mean of its up and down

942 stroke amplitudes. B: position of the Tongue Tip $(P(T T))$ and of the Lower Lip $(P(L L))$;

943 constriction events were displayed on the jaw cycle normalized between $-50 \%$ and $50 \%$

944 with $-50 \%$ at the beginning of the up stroke, $0 \%$ at the jaw maxima and $50 \%$ at the end of 945 the down stroke. 


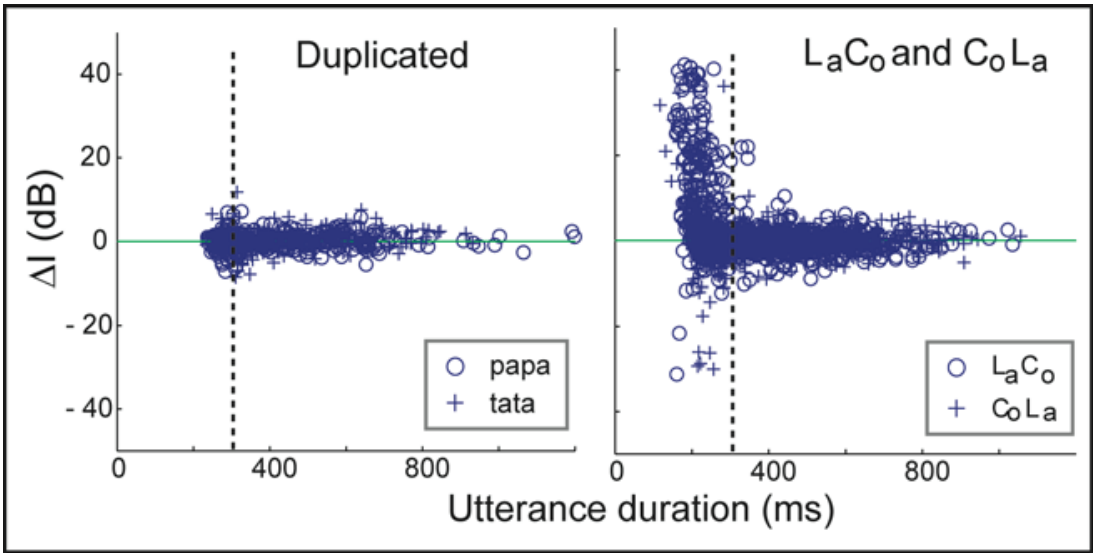

$947 \quad$ Figure 6: Intensity variation between the vowel after the labial constriction and the vowel 948 after the coronal constriction ( $\Delta I)$ against utterance duration for all subjects' duplicated 949 (left) and $L_{a} C_{o}-C_{o} L_{a}$ (right) productions. $\Delta I$ does not vary much with duration for 950 duplicated logatoms whereas duration around $300 \mathrm{~ms}$ (vertical doted line) appears as a 951 boundary for the range of possible $\Delta I$ values for $L_{a} C_{o}$ and $C_{o} L_{a}$ logatoms (see text). 


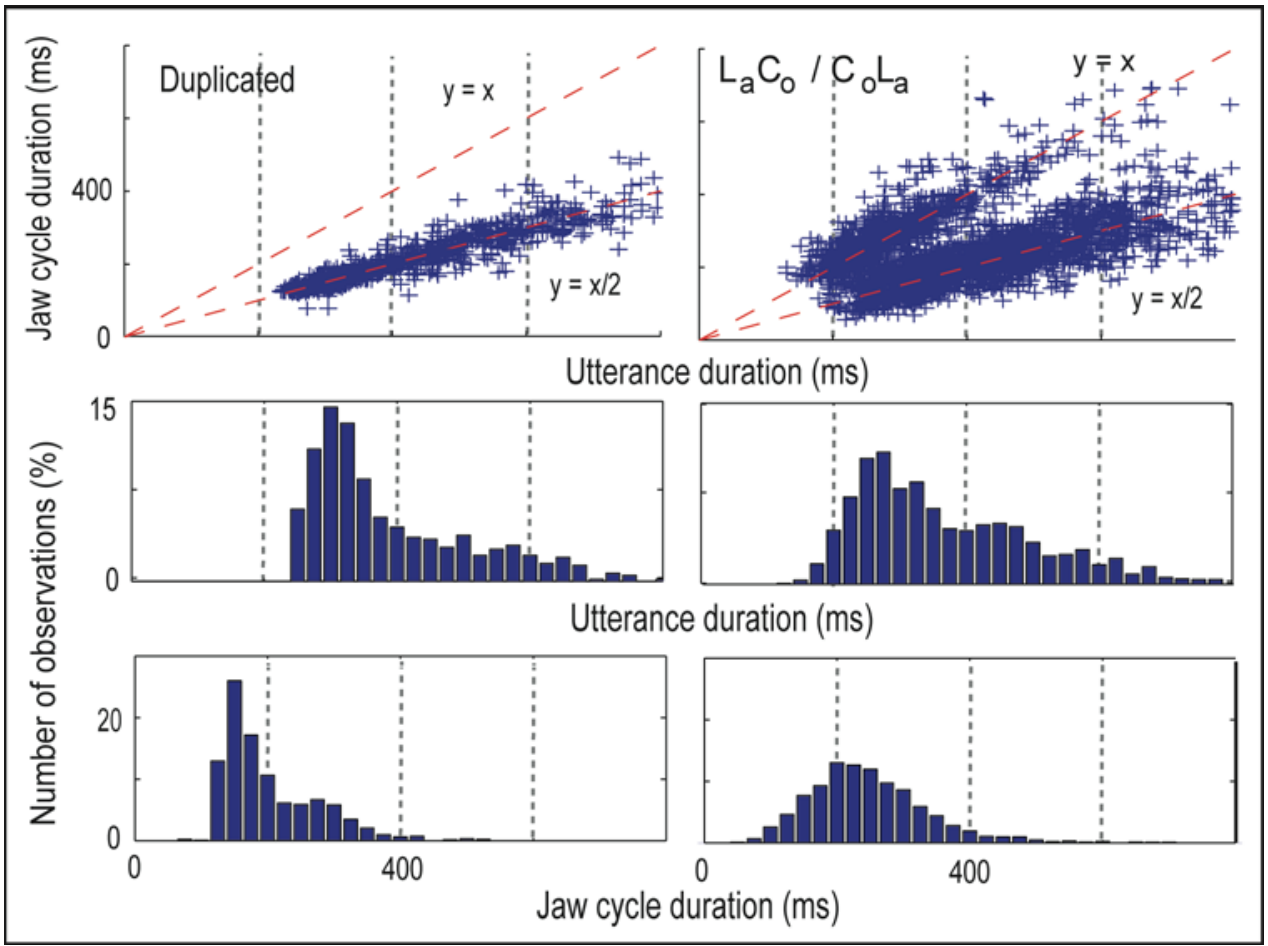

953 Figure 7: First row: Jaw cycle durations against utterance durations for all speakers' 954 productions and separately for duplicated (left) and $L_{a} C_{o} / C_{o} L_{a}$ sequences (right).

955 Distribution splitting observed for the $L_{a} C_{o}$ and $C_{o} L_{a}$ groups shows that these disyllables 956 could be produced on a single jaw cycle whereas duplicated disyllables are always realized 957 on two jaw cycles. Second and third rows: distribution of utterance and jaw cycle durations 958 for all speakers' productions. The utterance durations tend to be shorter for the $L_{a} C_{o} / C_{o} L_{a}$ 959 group as compared to the duplicated one whereas the contrary tends to appear for the jaw $960 \quad$ cycle durations. 


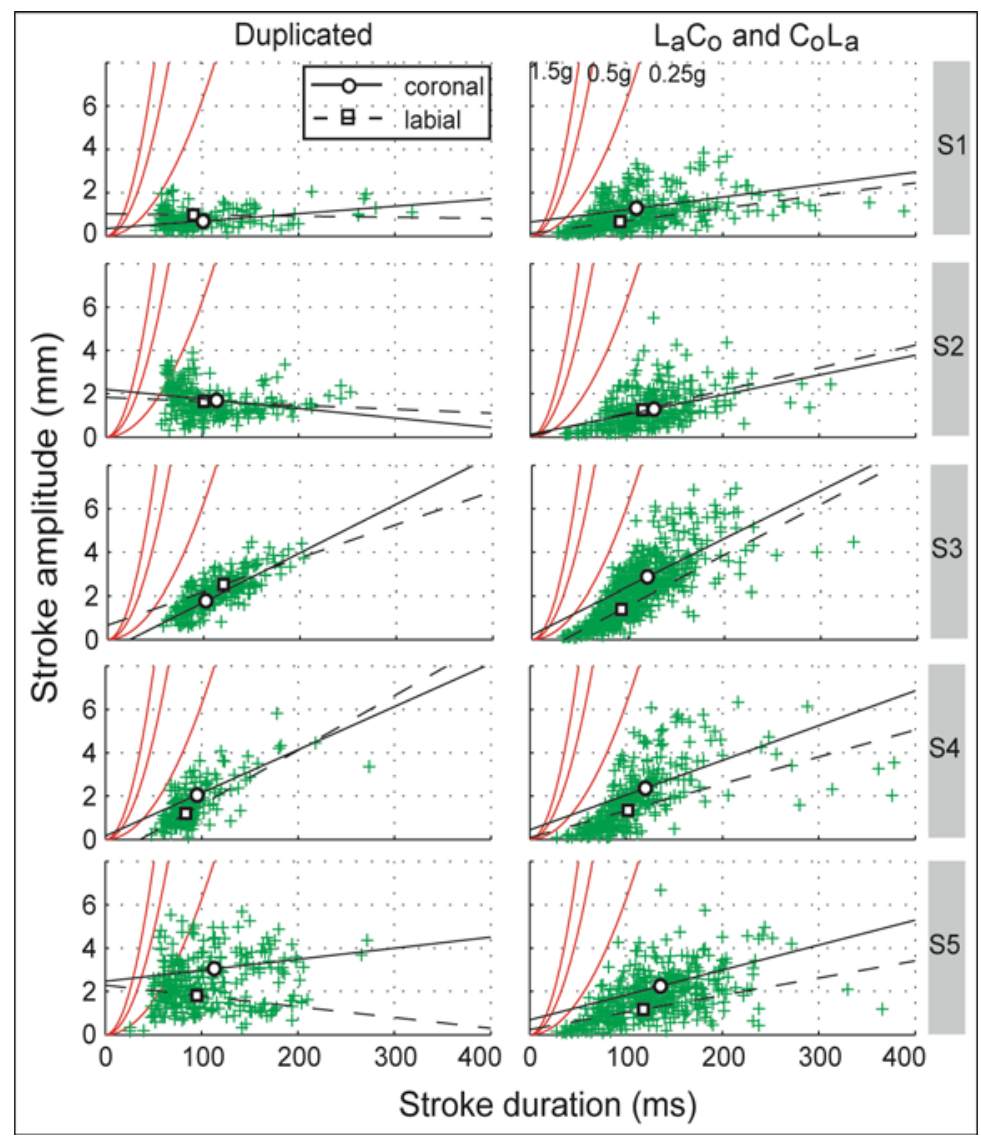

962 Figure 8: Jaw strokes amplitude (up and down) against duration during the acceleration 963 phase (when the disyllables are realized with two jaw cycles) for each speaker and 964 separately for duplicated (left column) and $L_{a} C_{o} / C_{o} L_{a}$ (right column) disyllables. The 965 parabolic curves are the theoretical minimum-time boundaries for mandible movements for 966 three control acceleration limits (from left to right: $1.5 \mathrm{~g}, 0.5 \mathrm{~g}$ and $0.25 \mathrm{~g}$, (see Nelson 967 1983)). Regression lines and distribution means (squares and circles) are displayed 968 separately for jaw strokes that come with labials and with coronals (see text for details). 


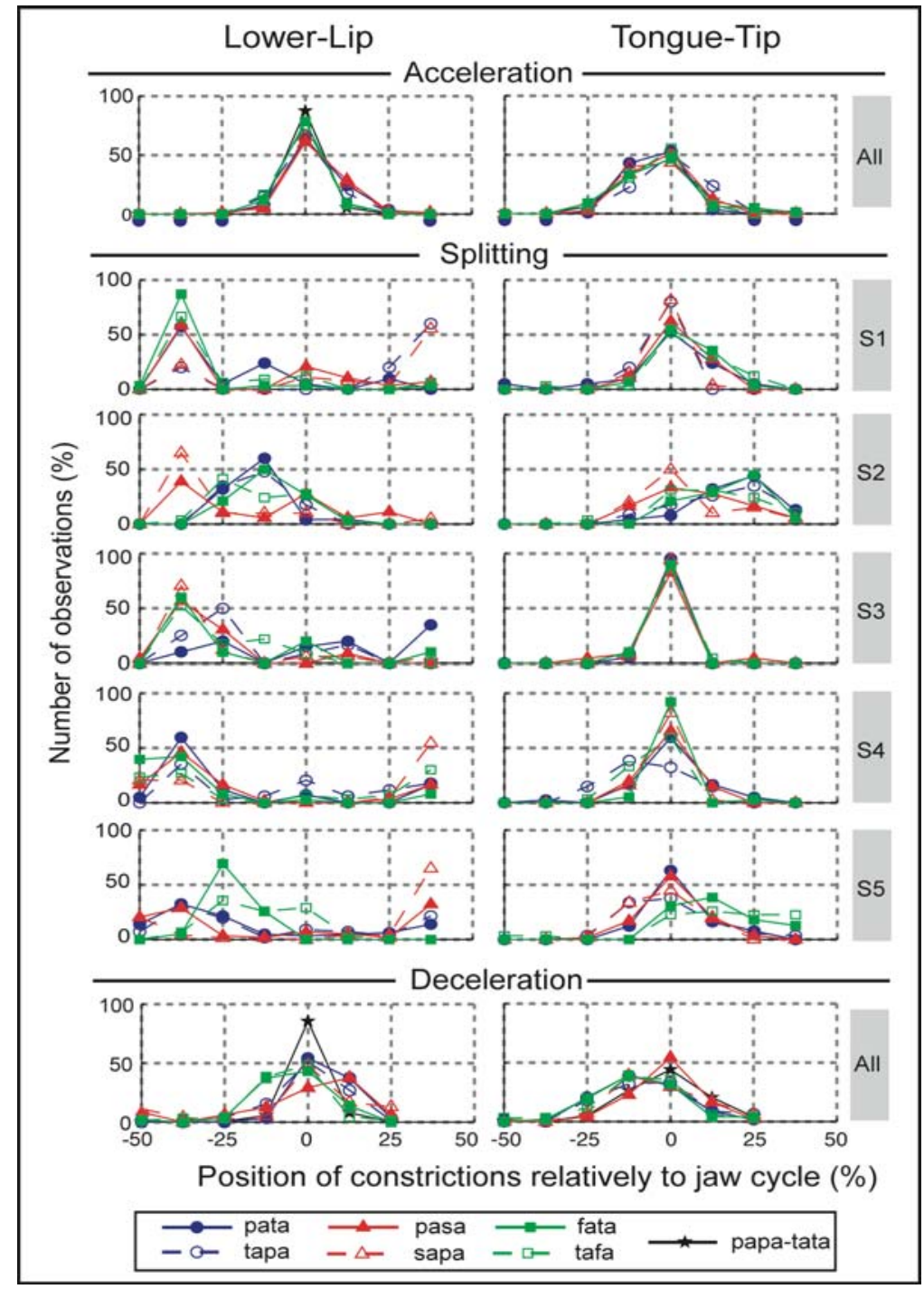

$970 \quad$ Figure 9: Distribution of speakers' productions according to the position of the Lower-Lip

971 (left) and the Tongue-Tip (right) constrictions relative to the jaw cycle. The three phases

972 (acceleration, splitting and deceleration) are plotted separately. For the acceleration and

973 the deceleration phases, histograms include all speakers taken together and both

974 duplicated and $L_{a} C_{o} / C_{o} L_{a}$ sequences. For the splitting phase (when utterances are realized

975 on a single jaw cycle), distributions are given for each $L_{a} C_{o}$ and $C_{o} L_{a}$ sequence and for

976 each speaker. 


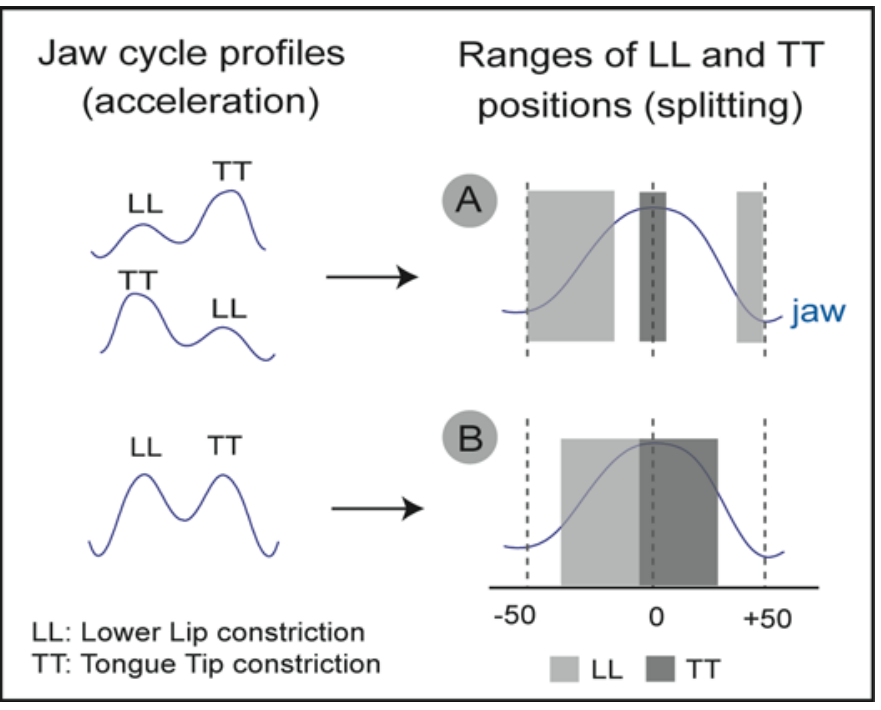

978 Figure 10: Coordination between the jaw and the constrictors from two jaw cycles for a

979 disyllable to a single one. Two patterns (A and B) of lower lip (LL) and tongue tip (TT)

980 constriction positions relative to the jaw cycle are observed when the two plosives are

981 realized on a single jaw cycle (splitting, right). They tend to correspond to specific jaw

982 motion profiles during the acceleration phase (left, see text for detail).

983

984 


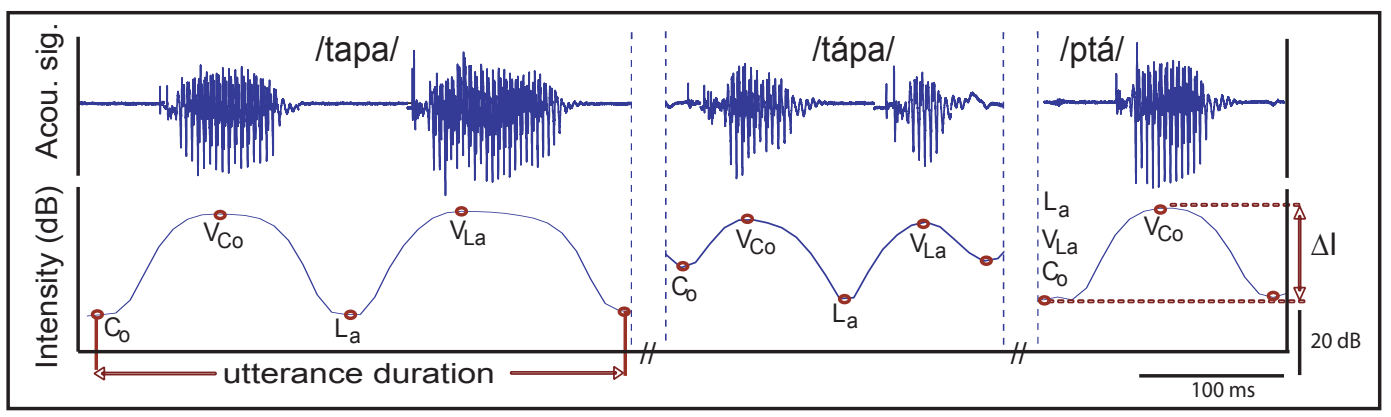




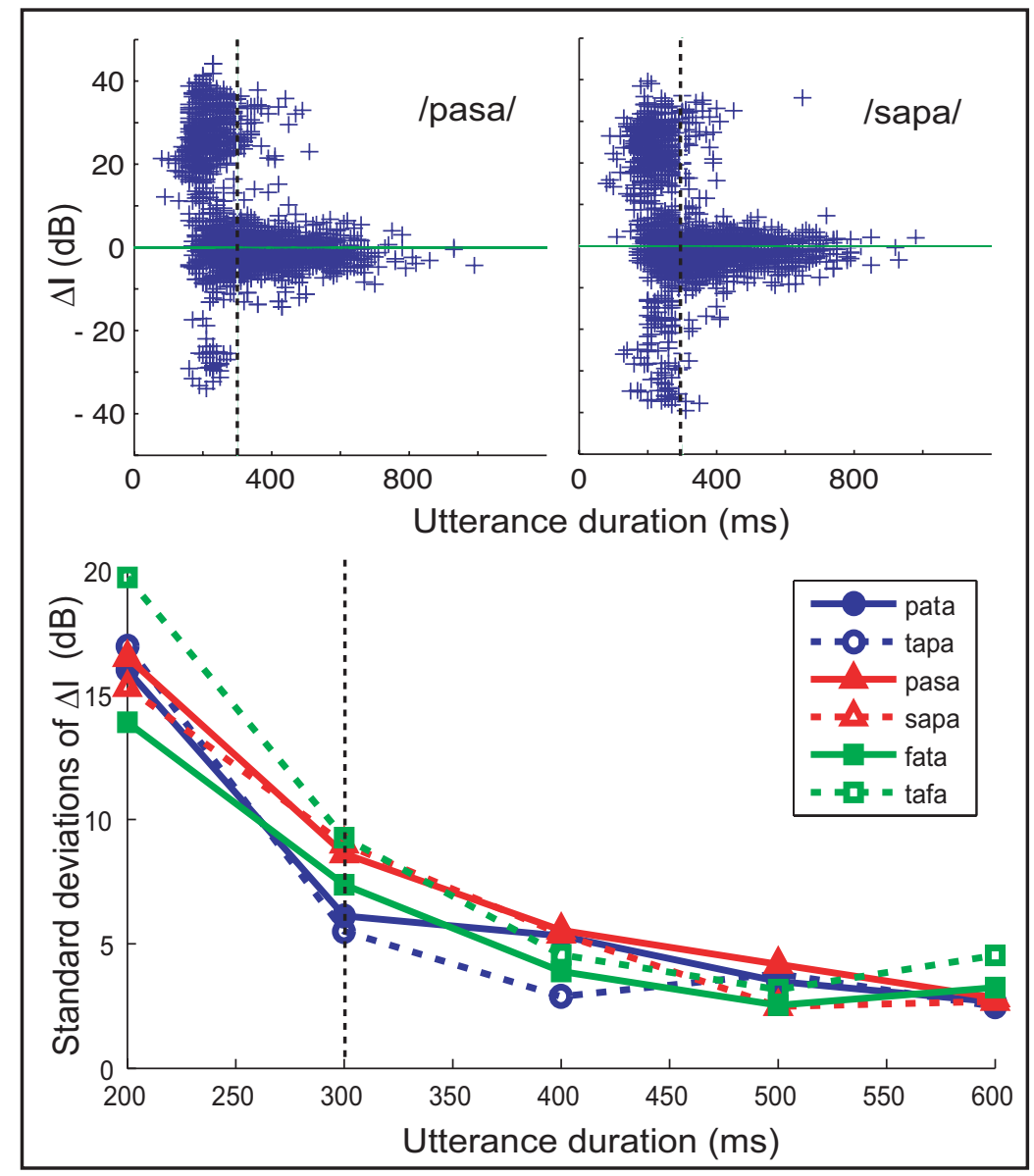




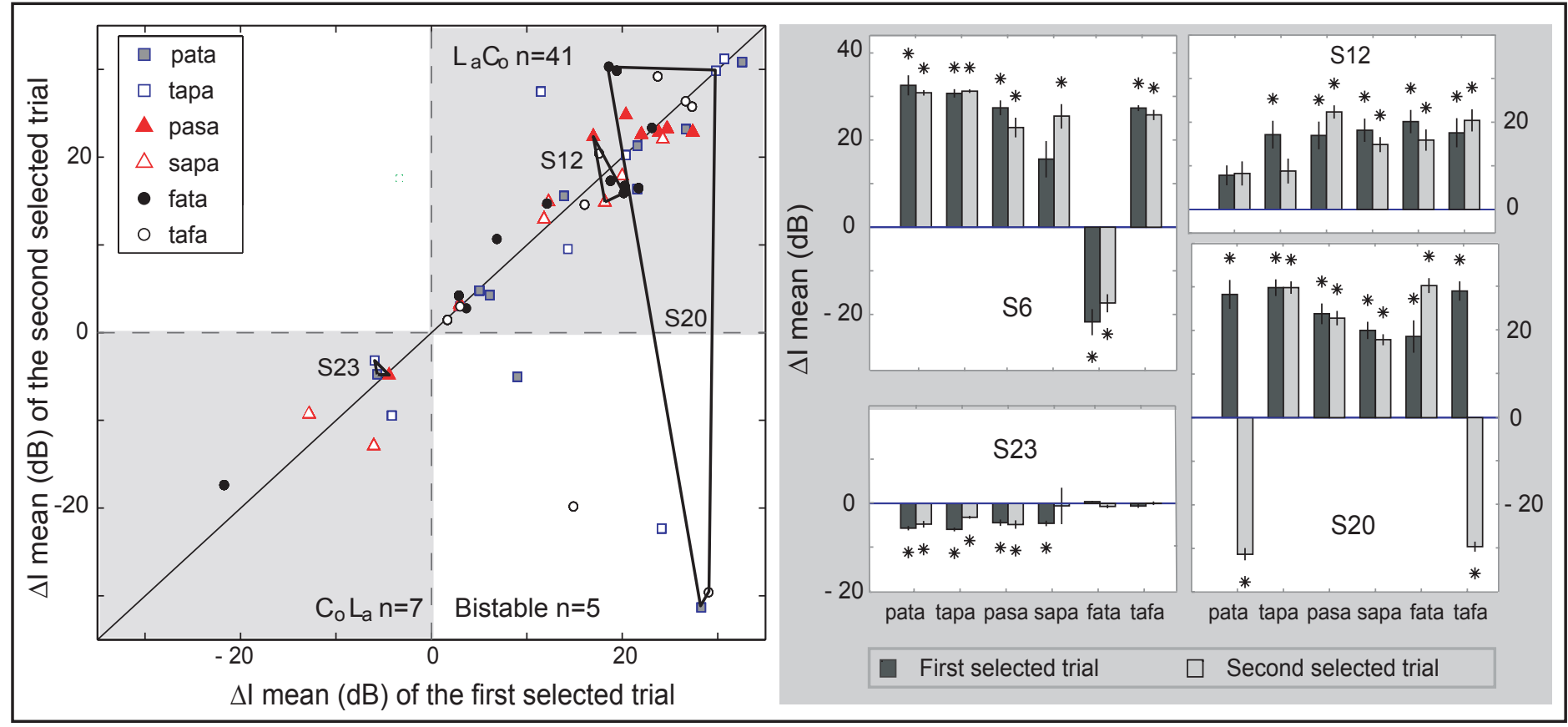




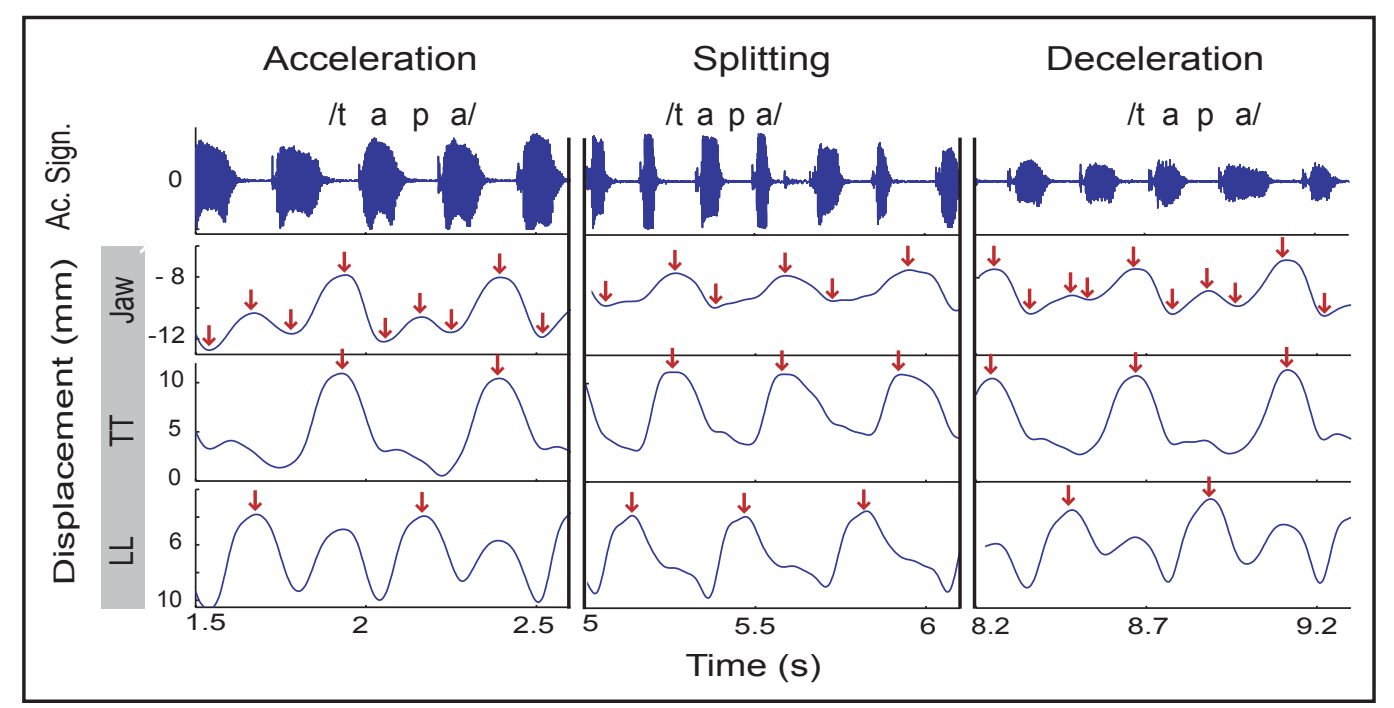




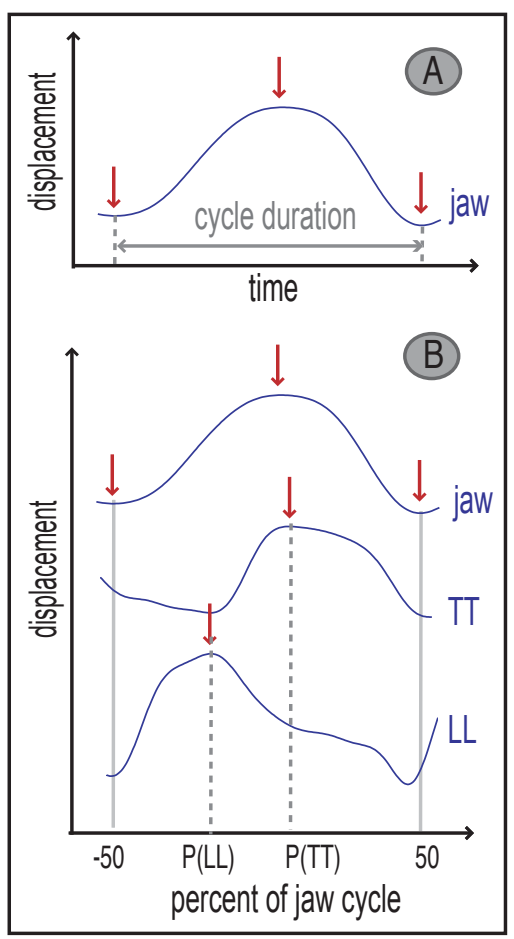




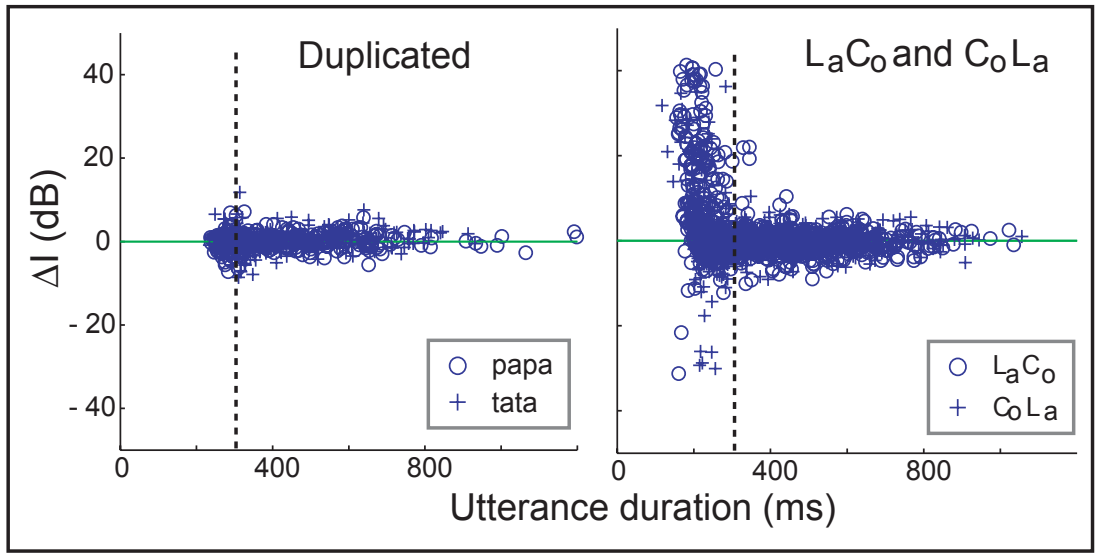




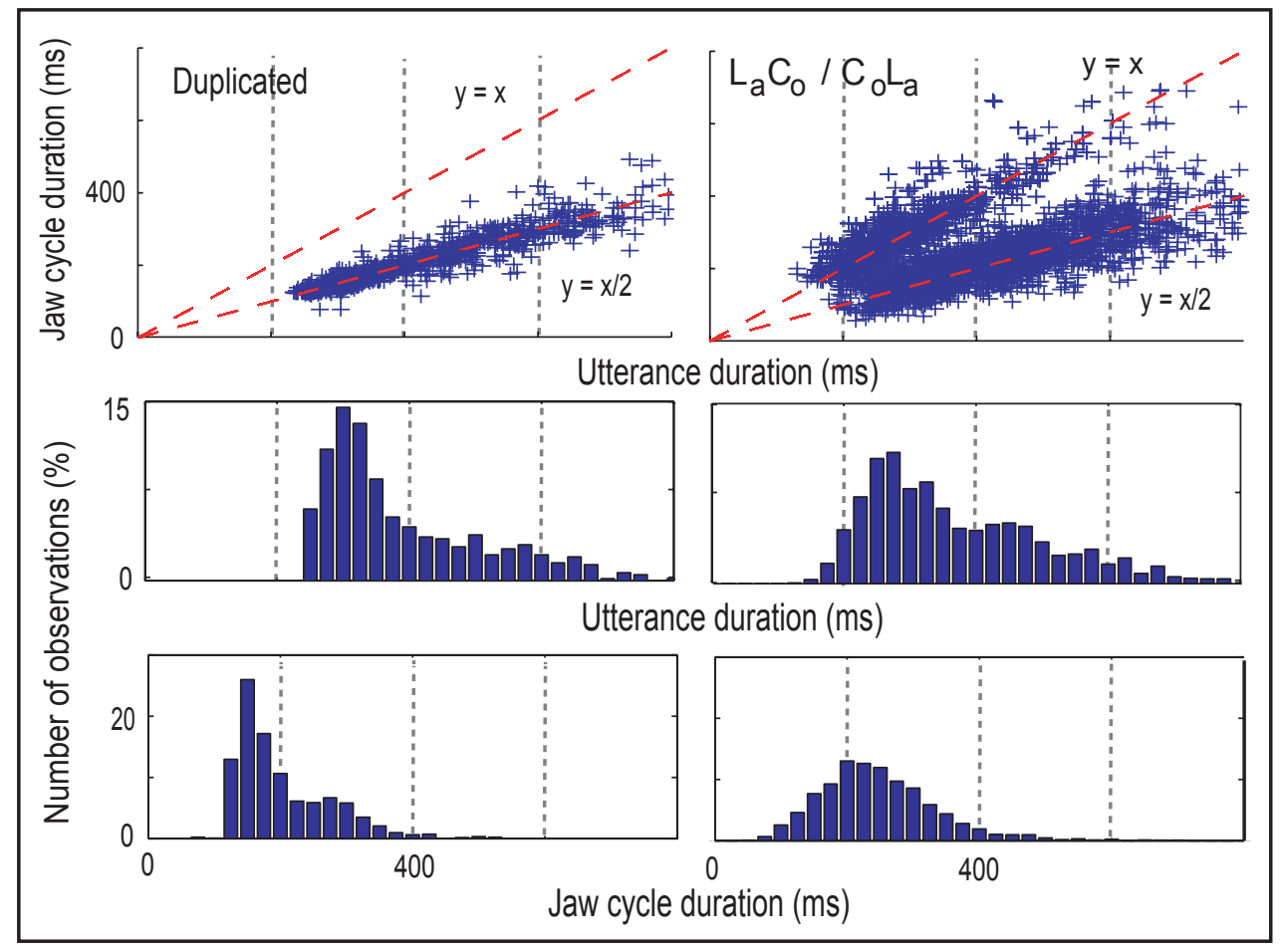




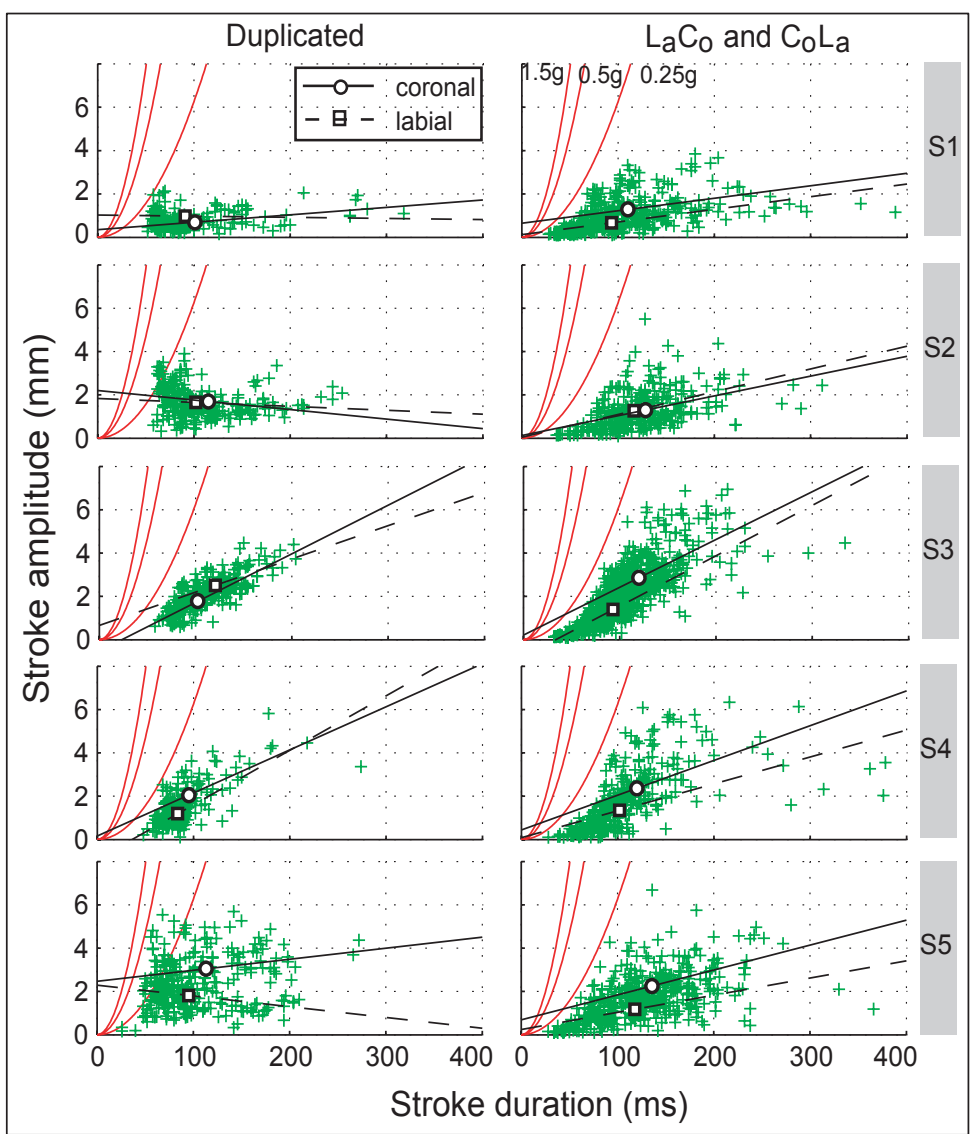




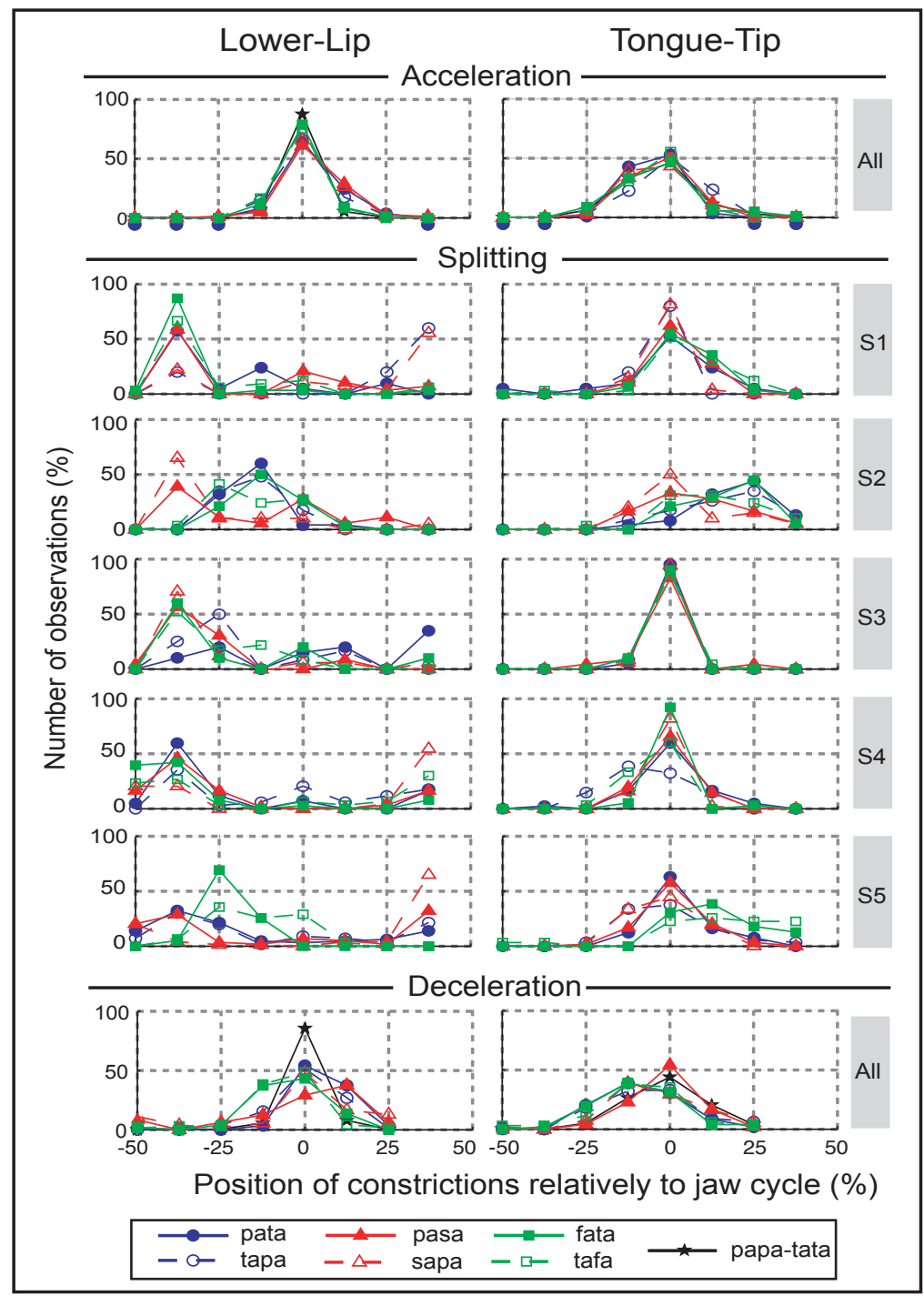




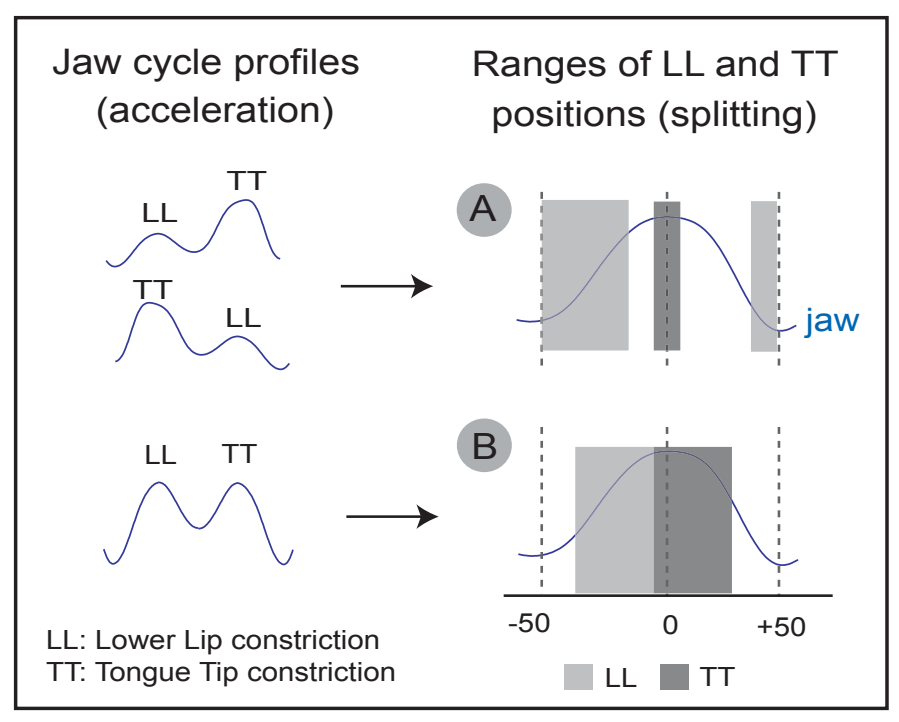

